University of Rhode Island

DigitalCommons@URI

Open Access Master's Theses

1995

\title{
Effectiveness of Enacting Stories Versus Discussing Art Projects to Facilitate Story Comprehension and Recall
}

Tina Hopkins

University of Rhode Island

Follow this and additional works at: https://digitalcommons.uri.edu/theses

\section{Recommended Citation}

Hopkins, Tina, "Effectiveness of Enacting Stories Versus Discussing Art Projects to Facilitate Story Comprehension and Recall" (1995). Open Access Master's Theses. Paper 1722.

https://digitalcommons.uri.edu/theses/1722

This Thesis is brought to you for free and open access by DigitalCommons@URI. It has been accepted for inclusion in Open Access Master's Theses by an authorized administrator of DigitalCommons@URI. For more information, please contact digitalcommons-group@uri.edu. 


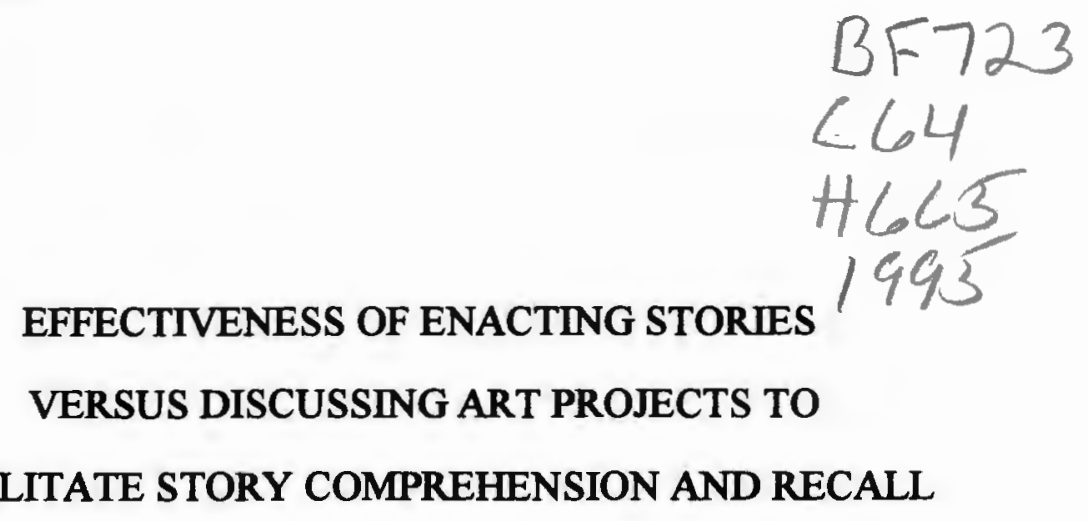

BY

TINA HOPKINS

A THESIS SUBMITTED IN PARTIAL FULFILLMENT OF THE

REQUIREMENTS FOR THE DEGREE OF

MASTER OF ART

IN

SPEECH LANGUAGE PATHOLOGY

$$
36249828
$$

UNIVERSITY OF RHODE ISLAND 


\section{ABSTRACT}

Story Enactment has been found to be an effective follow-up to reading for enhancing comprehension. This study was designed to determine if combining art projects with discussions could be as effective as enacting stories as follow-up activities to enhance story comprehension and recall The subjects participating in this study were twelve children (four groups of three children each) from the same PreKindergarten/Kindergarten class at Carriage House Day Care in Cranston, RI. The children participated in four onehour small group story and activity sessions within their regular preschool setting. Two of the sessions used enacting the story (Story Enactment) as the follow-up activity while the other two sessions used discussing an art project (Art Project Discussion) as the follow-up activity. After each session, the children individually answered comprehension questions and retold the story. It was found that there were no significant differences between retelling and comprehension measures in the story enactment versus art discussion activities. Both activities were equally effective in facilitating comprehension and recall of the stories.

Although there were no significant differences between the activities, some qualitative differences between activity types were observed and group dynamics emerged. During Story Enactment the children interacted cooperatively while during the Art Project Discussion they worked individually. Secondly, during the Story Enactment, child conversation focused on regulating and commenting on actions while during the Art Project Discussion child conversation focused on what picture to draw, what colors to use, and what happened in the story. Qualitative differences were also noted in type of supports provided, content of the discussions, and references to gender. Both activities were successful but how they arrived at the end point was different because the nature of 
the tasks was different. Thus, combining art project and discussion creates a method that is as effective as Story Enactment, there may be some qualitative differences. One method may be more desirable than the other for specific objectives and classroom conditions. 


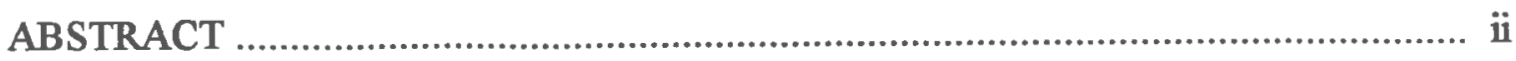

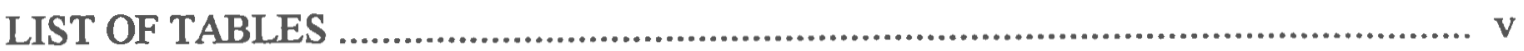

Chapter

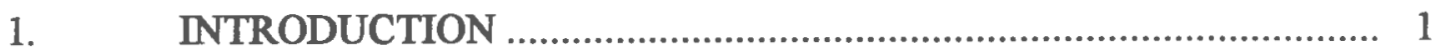

2. METHODOLOGY .............................................................. 5

Subjects

Story Stimuli

Design

Procedures

3. RESULTS 14

Quantitative

Qualitative

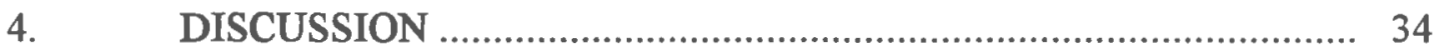

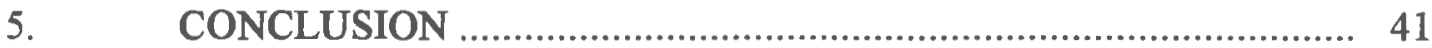

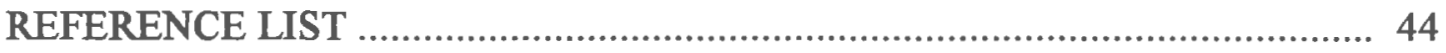

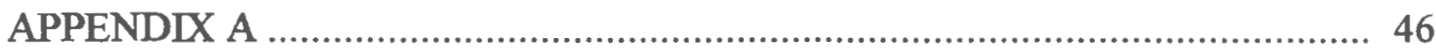

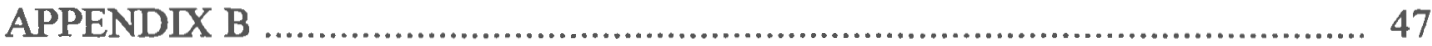

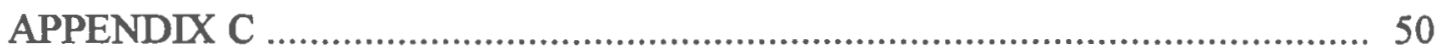

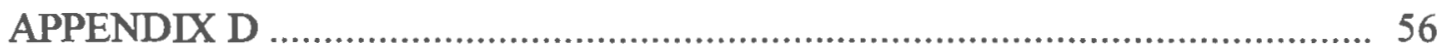

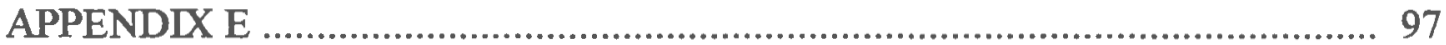

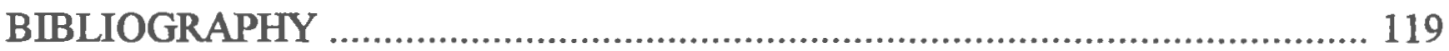


Table

1. Identifying Information .......................................................................... 6

2. Story Comparison ..................................................................................... 7

3. Order of Presentation ................................................................................. 7

4. Means and SDs for Comprehension and Recall Measures in Enactment Versus Art and Discussion .................................................. 14

5. Roles During the Activities .............................................................. 18

6. Extent to which Text was Followed During Sessions .............................. 22

7. Ratings for Measures of Recall, Comprehension and Events ...................... 26

8. Comparison of Support During Telling with Retelling and Comprehension Performance 


\section{CHAPTER I}

\section{INTRODUCTION}

Recent emphasis in the literature on story reading suggests that teachers and speechlanguage pathologists need to go beyond exposing children to stories to ensure their comprehension (Beck \& McKeown, 1981; Billingsley \& Ferro-Almeida, 1993; Fielding \& Pearson, 1994; Hoggan \& Strong, 1994). Since comprehension entails making personalized interpretations of texts, it is proposed that follow-up activities can activate understanding by permitting children to personalize the text (Hoggan \& Strong, 1994; Pellegrini \& Galda, 1982). Three such follow-up activities are story enactments, discussions, and art projects.

The literature suggests that story enactments have become an established method used to increase comprehension. It also suggests, that while discussions and art projects can be successful facilitators of comprehension, neither of these follow-up activities alone are as successful as story enactments for increasing comprehension in young children (Pellegrini \& Galda, 1982). In this study, a comparison was made between a combination of a discussion and an art project (called an Art Project Discussion) and a Story Enactment to see if this combination of activities would be as successful as the Story Enactment alone. This comparison could provide teachers and speech language pathologists with an alternate means of successfully increasing story comprehension.

Recent studies in the literature suggest that enactment of stories facilitates story recall and comprehension. Saltz and Johnson (1974) found that young children who were taught how to enact imaginary stories were significantly superior to controls, who did not 
enact stories, on a number of measures of social and cognitive development. Pellegrini (1984) examined the effectiveness of thematic-fantasy play training in facilitating children's immediate and delayed story recall. He found that reenacting stories was generally more effective than asking questions to help children recall story events and identify differences and similarities between stories. Other authors also discussed how active experiences with stories through thematic-fantasy play allow children to perform better on story recall (Silvern, Taylor, Williamson, Surbeck, and Kelley, 1986). Knipping (1993) observed that dramatic play allows the actors and audience to make decisions about character roles and props, which in turn forces them to think about the story in detail. Dramatic play provides children with the opportunity to "re-see" the story which fosters the children's sense of story structure. The most essential components tend to get included in the dramatization while the irrelevant details do not. Martinez (1993) instituted dramatic story reenactments in a kindergarten classroom and found that, by spring, children spontaneously reenacted stories. These spontaneous reenactments provided the children with opportunities to increase comprehension of stories. Story Enactments are an established method used to increase story comprehension that are frequently used as follow-up activities to telling stories to young children.

Another popular follow-up activity for young children is art projects. Commercial publications are flooded with suggestions for follow-up art projects designed to link children personally to the stories they have heard or read. Feldman (1991) and Herr (1990) present many different types of art projects that preschool teachers can use to connect children to the stories they hear. Milliken (1992) has patterns for art projects for teachers to use after reading specific stories. Swanson (1994) discussed how adultdirected art projects were often used in her nursery school setting as activities after story readings. Most of the literature on the value of follow-up art projects focuses on how they increase children's motivation to read and retell (Bookbinder, 1975; Harp, 1987; Hoggan 
\& Strong, 1994; Macey, 1978). Although it is implied that follow-up art projects will improve comprehension, few studies actually report concrete results on the effects. Authors imply that the increased motivation for children to retell while describing their art work will improve comprehension. They do not, however, provide any concrete evidence for this improved comprehension (Bookbinder, 1975; Harp, 1987; Hoggan and Strong, 1994; Macey, 1978).

There are also many studies advocating the importance of using discussions to facilitate story comprehension. Watson (1994) speculates that active participation in a discussion during story reading improves comprehension in children because it encourages attention to the story. Goldenberg (1993) stated that discussions help children pull out important information from the story. Alverman (1991) observed that discussions stimulate thinking and guide students' interpretations of reading selections. The above studies all focus on ways that discussions create a deeper understanding of the text and therefore increase comprehension. Many studies (Watson, 1994; Goldenberg, 1993; Alverman, 1991) focus on different ways to use story discussions, but little or no literature is available that specifically investigates the value of discussing a story during an art project to help enhance story comprehension.

Although there are references in the literature to the effectiveness of enactments, discussions, and art projects, little has been done to compare these three approaches. There is, however, one notable exception. Pellegrini and Galda (1982) compared story enactment, adult-lead discussion, and drawing to see which was the most effective facilitator of story comprehension. Pellegrini and Galda's study found that story enactment was the most effective and that enacting specific character roles seemed to have a direct effect on the children's ability to retell stories. They also noted that engaging in discussion was less effective than enacting but more effective than drawing. 
The literature provides teachers and speech language pathologists with follow-up activities to increase comprehension of stories. Story Enactment is successfully used as an approach by teachers and speech language pathologists to facilitate comprehension. Teachers frequently use art projects as follow-up activities so that the children can have a concrete project to bring home to parents. Although the children enjoy these art activities, teachers need to do more than just assign art projects to have any effect on story comprehension. Discussions are also used as a follow-up activity to facilitate comprehension. When working with young children, it is often difficult to keep their attention focused on a discussion without inchuding something concrete for them to focus on. Pellegrini and Galda showed that story enactment was more successful than a discussion which was more successful than an art project. This study combines art projects and discussions (called Art Project Discussion) to see if this combination can be as successful as Story Enactment and to ultimately provide teachers and speech language pathologists with a different, equally successful means of increasing comprehension. 


\section{CHAPTER II \\ METHODOLOGY}

SUBJECTS:

The subjects were selected from children who participated in the Carriage House Day Care program, a private day care center in a suburban area in Rhode Island. Twelve of the 19 children in the preschool were randomly selected to participate and were allowed to do so with parental consent. Twelve children ( 4 groups of 3 children) were selected in order to permit all children to be seen each day by the same examiner ( 1 session with each group) and to permit the children to be individually assessed for recall and comprehension.

Participating children, aged 4 years 5 months to 6 years 3 months, were all in the same PreKindergarten/Kindergarten class. Of the twelve children, seven were girls and five were boys. The children came from middle to upper middle class families. Parental professions included nurses, college professors, business men and women, a librarian, an architect, a fireman, a policeman, and a newspaper editor. None of the children had any identified hearing or visual problems, according to parental reports based on the children's most recent physical examinations. However, one child was identified as having an ear infection during the project, which may have resulted in a mild conductive hearing loss. Table 1 contains a list of identifying subject information. 
Table1

Identifying Information

\begin{tabular}{llllllll}
\hline & Child & Sex & Age & & Child & Sex & Age \\
\hline \multirow{3}{*}{ Group 1 } & 1 & F & 5 yrs 0 mo & & 7 & F & 6 yrs 3 mo \\
& 2 & F & 6 yrs 3 mo & Group 3 & 8 & M & 4 yrs 7 mo \\
& 3 & M & 5 yrs 5 mo & & 9 & F & 5 yrs 0 mo \\
& & & & & & & \\
\hline
\end{tabular}

These twelve children were all exposed to at least one story reading a day at school and often as many as four and five readings. In preparation for this project their classroom teacher read them three stories which the investigator asked them to retell and had them answer questions about.

\section{STORY STIMULI:}

Four stories that the children had not been exposed to in the day care setting were the stimuli used for the project. The stories were Stone Soup (Brown, 1947), Strega Nona (DePaola, 1975), Blueberries for Sal (McCloskey, 1948) and Sylvester and the Magic Pebble (Steig, 1969). The plot structure (Glenn and Stein, 1980), difficulty of story concepts, readability (Fry, 1969), and length are compared in Table 2 ( see page 7).

Although the stories were not completely identical, they were judged to be comparable on a number of dimensions. These dimensions included similarities of narrative level, numbers of characters, number of episodes, narrative structure, enactability of the stories, readability, and length. These similarities, and the fact that children have tended to enjoy them, were the reasons they were selected. 
Table 2--Story Comparison

\begin{tabular}{lllll}
\hline & Stone Soup & Strega Nona & Blueberries for Sal & Sylvester \\
\hline Characters: & $\begin{array}{l}\text { 3 soldiers } \\
\text { townspeople }\end{array}$ & $\begin{array}{l}\text { Strega Nona } \\
\text { Big Anthony }\end{array}$ & $\begin{array}{l}\text { Little Sal, Sal's mom } \\
\text { Baby \& Mother Bear }\end{array}$ & $\begin{array}{l}\text { Sylvester } \\
\text { Parents, animals }\end{array}$ \\
\hline $\begin{array}{l}\text { Plot } \\
\text { Structure: }\end{array}$ & $\begin{array}{l}\text { Complex } \\
\text { Episode }\end{array}$ & $\begin{array}{l}\text { Complex } \\
\text { Episode }\end{array}$ & $\begin{array}{l}\text { Complex } \\
\text { Interactive } \\
\text { Episode }\end{array}$ & $\begin{array}{l}\text { Complex } \\
\text { Interactive } \\
\text { Episode }\end{array}$ \\
\hline $\begin{array}{l}\text { Story } \\
\text { Concepts: }\end{array}$ & trickery & $\begin{array}{l}\text { magic } \\
\text { consequences }\end{array}$ & consequences & $\begin{array}{l}\text { magic } \\
\text { consequences }\end{array}$ \\
\hline Readability: & grade 1 to 2 & grade 2 & grade 2 & grade 2 \\
\hline Length: & 31 pages & 28 pages & 29 pages & 30 pages \\
\hline
\end{tabular}

\section{DESIGN:}

The subjects were randomly assigned to four groups of three children, with all groups experiencing both the Art Project Discussion and Story Enactment conditions. Two of the groups experienced the combined art and discussion task first (Art Project Discussion), and the other two groups experienced the Story Enactment task first. In this withinsubject, counterbalanced design, all children were exposed to all four stories with the order of presentation rotated. The order of presentation of the stories was as follows:

Table 3--Order of Presentation Activity:

\section{Group 1 Story 1 Story 2 Story 3 Story 4}

Group 2 Story 3 Story 4 Story 1 Story 2

\section{A - Enactment}

A - Enactment

B - Art/Discussion

B - Art/Discussion

A - Enactment

A - Enactment

B - Art/Discussion

B - Art/Discussion

\section{Group 3 Story 1} Story 2

Story 3

Story 4

Group 4 Story 3

Story 4

Story 1

Story 2
Activity:

B - Art/Discussion

B - Art/Discussion

A - Enactment

A - Enactment

B - Art/Discussion

B - Art/Discussion

A - Enactment

A - Enactment 
The independent variable was the type of follow-up activity, story enactment versus the art project discussion. The dependent variables were the following story comprehension and recall measures: overall retelling score, responses to comprehension questions, number of T-units, number of words contained in the retelling, and number of events remembered.

The story recall dependent variable was a retelling measure adapted from Murrow and Smith's (1990) scoring of children's free recall (see Appendix A). Children's transcribed stories were assigned 1 point for each of the following items included in their retellings: introduction, characters, setting, theme, resolution, and ending. In addition, the children received 1 point for including $0-50 \%$ of the story grammar components and 2 points for including $51-100 \%$ of the story grammar components. The children also received 2 points for telling the story in the proper order and 2 points for including any interpretive statements or explanations about how a character felt or why a character acted a certain way.

The number of T-units and words in the retellings were also counted to measure the quantity of output. T-units are defined as minimal terminal units consisting of one main clause plus any attached or embedded subordinate clauses or nonclausal structures.

Another dependent variable was responsiveness to the questions asked about the stories. Three knowledge questions, two comprehension questions, one application question and one analysis question were created for each story. Point values were assigned to each type of question depending on its level of difficulty. Knowledge questions, the easiest, assess recall and recognition and therefore receive 1 point for correct answers. Comprehension questions are more difficult; involving translating, interpreting, and extrapolating information; so the children received 2 points for correct answers. Application questions involve applying the information in the story to situations 
that are new or unfamiliar. Analysis questions involve breaking down the story into parts or forms. Application and Analysis questions are the most difficult so the children received 3 points for correct answers.

The retellings were also scored on a measure of events remembered. In order to obtain this measure, the number of events in the stories was calculated and divided by the number of events included by each child.

In addition to quantitative analyses, qualitative analyses were conducted. The qualitative analyses provided information about how the children interacted and permitted speculations about what factors might be affecting these interactions. Heath (1993) suggests that a deeper and richer understanding of language can come through such qualitative observations. In this study, investigator observations were made to address the following questions:

1. Were the children's affective comments about the Story Enactment different from those of the Art Discussion?

2. Were role selections affected by gender?

3. What social dynamic and peer interaction patterns emerged within the groups?

4. To what extent did the children rely on the text, vary from the text during the activities and include these variations in their re-retellings?

5. How much investigator support was required during the enactment, discussions, and retellings, and what was the effect on the results?

\section{PROCEDURES:}

The principal investigator served as the session facilitator which involved reading the story and then either enacting the story or making and discussing a story-related art 
project. (See Appendix B for details). These sessions took place in a closed office away from the children's classroom in the children's school and went as follows:

Story Enactment: 1. The investigator read the story to the children and then introduced the follow-up activity of acting. (Videotaped)

2. The children chose roles and set up the provided props.

3. The children then acted out the story using the book as a guideline when necessary. The investigator provided support as the group needed. Types of support included: suggesting lines if the children became stuck, reminding the children of the character's problem or feelings, directing actions, showing pictures, and making appropriate comments. (Videotaped)

4. The children individually retold the story and answered questions about the story. (Audio-taped)

Art \& Discussion: 1. The investigator read the story to the children and then introduced the follow-up art and discussion activity. (Videotaped)

2. The children helped to set up the room and the investigator introduced the art project by giving the children a cutout of an item that was included in much of the story. Then she had the children glue that item on their page and start drawing their pictures.

3. The children made and discussed their art projects using the book and their pictures to provide story events to discuss. The investigator provided support as needed. Types of support 
included: referring the children to the book for suggestions or elaboration, acknowledging and elaborating on children's comments, and asking leading questions to facilitate the discussion. (Videotaped)

4. The children individually retold the story and answered questions about the story. (Audio-taped)

Each group listened to the stimulus target story first. The title, author, and the reason to read was introduced. "Today, we are going to listen to the story and then we will (act it out or do an art project and discuss it). I want you all to listen closely to the story so that you can tell it to another teacher when we are done." The story was then read exactly as it was written with pauses and expression (about 10 minutes). Questions were not asked or comments were not made during the story by the investigator. If a child commented or asked a question, the investigator responded naturally by either acknowledging the comment or by answering the question.

After the story was completed, the children were then introduced to their follow-up activity. If it was the enactment, the investigator would say, "Today, we are going to act out the story we just heard. You will be able to use the book to help you act out the story." The children then chose the role they wanted, set-up the props from those available, and acted out the story with encouragement to refer to the book if needed. (See Appendix B for complete procedures.) The investigator played the role of narrator/stage manager. She held the book so the children could see the pictures (unless one of the children wanted to hold the book) and helped them follow the story. She let the children take the lead but offered suggestions if they became stuck or produced tangential or irrelevant remarks or acts. The investigator helped by suggesting lines, reminding the children of the character's problem or feelings, directing actions, showing pictures, and 
making appropriate comments. The investigator also reminded the children of the main theme and how elements related to this theme.

If the activity was the Art Project Discussion, the investigator would say, "Today, we are going to do an art project about the story we just heard. You will be able to use the book to heip you choose your art project." The investigator would then introduce the activity by giving the children a cutout of an item that was included in much of the story. The children then glued this cutout on their page and made an art project. They were encouraged to discuss what they were creating and how it related to the story. The investigator would also remind the children to refer to the book for suggestions or elaboration. (See Appendix B for complete procedures.) The investigator followed the children's lead during the discussion. If the children started talking about the story while doing their activity, she would acknowledge and elaborate on their comments. If the children did not make any comments or did not discuss the story, the investigator would lead them by making comments such as, "I like the part when Sal was following the bear."

After the children completed their activity, they were each taken to a separate room to assess retelling and comprehension. Three different examiners questioned the three children at the same time in three separate rooms. The children were randomly assigned to the examiners in a rotating order to ensure that all children were exposed to all examiners. The examiners were three teachers at the school who had previously participated in a training session where procedures for the testing of recall and comprehension were explained and demonstrated and were 'blind' to the study's hypotheses.

During the assessment phase of the session, each child was asked to tell the story to the randomly selected examiner. Each examiner followed a prepared format on how to ask the comprehension questions and on how to ask for the retelling. The examiner began by saying, "I heard you just listened to the story . I'd like to hear that story. 
Would you please tell it to me?" She then paused for about 5 seconds; if the child did not begin the story within this time she would say, "(character name) is in this story. Could you tell me what happened to him/her?" The examiner made comments like "wow", "really", and "and then what happened" to let the child know that she was listening. If a child stopped talking, the examiner used prompts that rephrased what the child just told them and then asked what happened after that. It was noted what types of prompts and how many were used to get the children to retell. Comprehension questions were not asked during the retellings.

After the child completed his or her retelling, the examiner asked, "Is there anything else?" When the child said, "no", the examiner said, "That was a great story. Now I am going to ask you some questions about that story." The examiner read the questions exactly as they were written. The examiner repeated each question only once if it was necessary. This part of the session was audiotaped. After each child completed their assessment session, they reported back to the investigator who thanked them for being a great helper and allowed them to choose a sticker. 


\section{CHAPTER III}

\section{RESULTS}

\section{QUANTITATIVE:}

Each child's score on a variety of measures was used to compare the results of Story Enactment versus Art Project Discussion. These measures included recall and comprehension scores, and numbers of T-units, words, and events. Table 4 summarizes the results.

Table 4--Means and SDs for Comprehension and Recall Measures in Story Enactment and Art Project Discussion Tasks

\begin{tabular}{|c|c|c|c|c|c|c|}
\hline & \multicolumn{3}{|c|}{ Story Enactment } & \multicolumn{3}{|c|}{ Art Project Discussion } \\
\hline & Mean & SD & P Level & Mean & SD & P Level \\
\hline Recall & 14.1 & 6.5 & 0.92 & 13.8 & 6.0 & 0.92 \\
\hline Comprehension & 16.0 & 5.4 & 0.67 & 15.1 & 4.6 & 0.67 \\
\hline T-units & 33.2 & 11.9 & 0.26 & 38.5 & 10.6 & 0.26 \\
\hline Words & 255.4 & 140.7 & 0.45 & 297.0 & 126.7 & 0.45 \\
\hline ML T-units & 7.3 & 1.8 & 0.80 & 7.5 & 1.8 & 0.80 \\
\hline Events & 28.7 & 14.8 & 0.98 & 28.8 & 14.1 & 0.98 \\
\hline
\end{tabular}

It was hypothesized that combining art and discussion as a follow-up activity would be as effective as using Story Enactment, an established method used to increase 
comprehension. The results of this study showed that there were no significant differences between the Story Enactment and Art Project Discussion activities on the various comprehension and recall means. Therefore, this combination of an art project and discussion was as effective as enacting a story on measures of recall and comprehension.

\section{QUALITATIVE:}

Additional analyses were done to determine if there were any qualitative differences in the children's performance both within and between the two activity types. These qualitative observations were made along the five question areas designed to focus on: affective comments, gender distinctions, social dynamics, reliance and variation from text, and investigator support (see page 9). The children's interactions during each group session were recorded and transcribed (See Appendix D) and then observations about these questions were made (See Appendix C). Observations of individual child differences were also noted.

Were affective comments about Story Enactment different from those of Art Project Discussion?

Although the children exhibited much excitement and animation during the sessions, there were few specific affective comments made directly about the activity type. There were six positive comments about the Story Enactment and only one positive comment about the Art Project Discussion. Positive comments about the Story Enactment included; "This is fun." and "Oooh, we haven't done this!" The positive 
comment about the Art Project Discussion came when the activity was introduced and Child 12 stated, "Oh goody". There were no recorded negative comments about either type of activity.

Although there were not many affective references made specifically to the follow up activities, the children enjoyed participating in this project. Their classroom teacher, who was not involved in conducting the project, noted that they discussed what they had done during the sessions and that they were very excited about them. When the investigator went into the classroom to get a new group, the children greeted her with comments like: "Is it my turn?" and "Can I go again?" Parents also made comments about how much their children enjoyed the activities. For example, Child 8's mother commented that he was really excited about the project and that he would explain exactly what his group did each day.

Were role selections affected by gender?

Any comments relating to the gender of the characters or comments relating to typically male or female roles were recorded from the videotapes. It was also noted when a child chose a character of the opposite sex.

Three children made two gender comments each, all occurring during the Story Enactment sessions. Only these three children; 1-Female, 4-Female and 5-Male; appeared to have any concerns about gender roles. Child 1 made the following two gender related comments: (to Child $3 \mathrm{M}$ ) "You could be one (a soldier) cause you're a boy." and "Im glad Im not Strega Nona. It's a boy." Child 4 and Child 5 got involved in a gender related discussion while picking characters during Blueberries for Sal because Child 5 did not want to be baby bear's mother, a female role. Child 4 was quick to tease him about 
having to be a girl character. However, when the investigator asked what could be done instead of having a mother bear, Child 4 suggested having a daddy bear instead. Children 4 and 5 also had an argument about who would be the king after receiving a donkey ear headband during Sylvester and the Magic Pebble. Child 4 ended the argument by stating, "You're the king and Im the queen and we're getting married (makes kissing noises)." For the most part, the children chose their characters without any regard to the gender of the character. In fact, five out of seven females chose male characters and two out of five males chose female characters at some point during the two Story Enactments.

It appeared that gender distinctions were only relevant within the Story Enactment and only a small number of children were affected. Two girls, Child 1 and Child 4, and one boy, Child 5 made two gender related comments each. The rest of the children chose their characters without any regard to the gender of the character.

What social dynamic and peer interaction patterns emerged within the groups?

As the children interacted, the investigator observed certain social roles that emerged within the sessions. It was also noted that the manifestation of these roles differed between Story Enactment and Art Project Discussion. The types of social roles, defined below, included:

Leader- requested information or actions; made assertive comments and statements; gave commands or directions to others; most frequently initiated and extended the discussion or character role.

Helper- requested information or actions; provided suggestions and gave physical assistance to the others in the group; most frequently maintained and extended the discussion or character role; focused on helping others.

Participant- requested information or actions; did not always follow the directions of others; most frequently maintained and extended the discussion or character role; focused on own work or role (self). 
Follower- responded to others' actions or comments; needed supports in order to participate; maintained discussion and character role but produced few initiations or extensions.

A list of what roles the children took within Story Enactment versus Art Project Discussion are listed in Table 5, and a discussion of these group dynamics, follows.

Table 5 -- Roles During the Activities

\begin{tabular}{|c|c|c|c|}
\hline Group & Child & Story Enactment & Art Project Discussion \\
\hline 1 & $\begin{array}{l}1 \\
2 \\
3\end{array}$ & $\begin{array}{l}\text { follower } \\
\text { follower } \\
\text { leader }\end{array}$ & $\begin{array}{l}\text { follower } \\
\text { follower } \\
\text { participant }\end{array}$ \\
\hline 2 & $\begin{array}{l}4 \\
5 \\
6\end{array}$ & $\begin{array}{l}\text { participant } \\
\text { participant } \\
\text { participant }\end{array}$ & $\begin{array}{l}\text { participant } \\
\text { participant } \\
\text { participant }\end{array}$ \\
\hline 3 & $\begin{array}{l}7 \\
8 \\
9\end{array}$ & $\begin{array}{l}\text { helper/leader } \\
\text { follower } \\
\text { helper }\end{array}$ & $\begin{array}{l}\text { helper } \\
\text { follower } \\
\text { helper }\end{array}$ \\
\hline 4 & $\begin{array}{l}10 \\
11 \\
12\end{array}$ & $\begin{array}{l}\text { follower } \\
\text { follower } \\
\text { follower }\end{array}$ & $\begin{array}{l}\text { follower } \\
\text { follower } \\
\text { follower }\end{array}$ \\
\hline
\end{tabular}

Within each group the children assumed the roles defined above. The dynamics of the groups were in part determined by the roles of the members.

In Group 1, a clear leader, Child 3, emerged within the Story Enactment but not during the Art Project Discussion. He helped to keep the Story Enactment flowing by giving Child 1 and Child 2, females, directions and by giving them an example to follow. For example, during the Story Enactment of Stone Soup, Child 3 started setting the table and dished out the soup, and the other children then sat down to eat the soup. Child 3 
then told the other children that it was time to dance, a direction which kept the enactment moving. During the Art Project Discussions, however, Child 3, who was a leader during the Story Enactment, became a participant. He no longer gave the other children directions; instead he focused on his own work. Child 1 and Child 2 remained followers by glancing at his work to see what he was doing and by following the investigator's lead to discuss the story. Group 1 needed about the same amount of investigator support during both the Story Enactment and Art Project Discussion sessions.

In Group 2, comprised of one female and two males, no leader emerged during either the Story Enactment or Art Project Discussion. During the Story Enactment, all three children understood their roles and the sessions progressed through the story events with little investigator involvement. The children were participants because they were focused on their own work and what their character should be doing. Each child knew what he or she should be doing so it wasn't necessary for a leader to take over and direct the other children. The same held true for the Art Project Discussions; the children were active participants and the sessions were very productive and included many important events from the stories. Group 2 was by far the most independent group during both Story Enactment and Art Project Discussion activities with all three children making important contributions. The children needed little support during either activity, however, there were occasions during both activities when they needed to be redirected because they became tangential.

In Group 3, comprised of two females and one male, two helpers and one follower emerged during both activities. Child 7 and Child 9 helped Child 8 decide what to do and say during the Story Enactment. Child 7 and Child 9 helped Child 8 without taking over and telling him what to do. They used comments and suggestions to allow him to participate in the Story Enactment. During the Art Project Discussion, they helped him to discuss the story and to make his art project by asking him questions and by commenting 
on his work. The discussions were very productive and included many important events from the story. Thus, Group 3 needed low to moderate investigator support during both the Story Enactment and the Art Project Discussion.

In Group 4, comprised of two females and one male, no leader emerged during either the Story Enactment or during the Art Project Discussion. The children had difficulty acting out the events in the story without support and directions from the investigator. Indirect leading questions, suggestions, pauses and comments to help the children act were useless because the children would stand and wait until the investigator gave them explicit directions about what they should do or say. Group 4 also had difficulty during the Art Project Discussion because they would make many irrelevant comments and needed encouragement to participate in the discussion. Group 4 needed a high amount of investigator support during both activities.

The social dynamics of each group was different. Group $1 \mathrm{had}$ a leader and two followers during the Story Enactments and a participant and two followers during the Art Project Discussion. Group 2 had three participants during both activities. Each of these could have served as leaders if placed in a group with less competent peers. Group 3 had two helpers and a follower during the two activities while Group 4 had three followers during both activities. Despite these differences in overall group dynamics, most of the children were consistent in the fact that the roles they assumed during the Story Enactment was similar to the roles they assumed during the Art Project Discussion. The exceptions were Child 1 in Group 1, who changed from a leader during the Story Enactment to a participant during the Art Project Discussion, and Child 7 in Group 3, who was a helper/leader during the Story Enactment and just a helper during the Art Project Discussion.

Another difference noted between Story Enactment and Art Project Discussion was in the type and frequency of interactions. During the Story Enactment, the children 
worked together to create a play and group negotiations emerged. During the Art Project Discussion, the children commented on their own pictures and how their picture related to the story. Thus the children worked individually and not cooperatively. This is why Child 1 in Group 1 was able to change his role from a leader during the Story Enactment to a participant during the Art Project Discussion. In the Art Project Discussion it was not necessary for him to tell the other children what to do. He could work on his picture and discuss the story without getting the other children to participate. The nature of interaction differed between the two activities.

In summary, there were both similarities and differences in group dynamics across activities. Each group was made up of children who assumed particular roles, which tended to impact the dynamics. The way each individual group interacted during the Story Enactment was similar to the way they interacted during the Art Project Discussion. However, for all children and all groups, the children worked together more cooperatively during the Story Enactment while during the Art Project Discussion they worked more independently.

To what extend did the children refer to the text and vary from the text during the activities?

The children used the text in different ways during the Story Enactment and Art Project Discussion. During the Story Enactment, the book was used as a guideline as to what events the children needed to be acting out. The children saw the pictures and followed the events on the pages which were turned as the story was acted out. During the Art Project Discussion, the book was kept on the center of the table, and the children were encouraged to look at it throughout the session. The children used it to select which 
events they wanted to draw and to give them different events to discuss while creating their art work. The events the children chose to discuss however, often were isolated and not presented in a sequential fashion. Also the events discussed depended on what interested the children, so certain events were not included.

The criteria for deciding how closely the text was followed was slightly different for the two activities. During the Story Enactment, the criteria was whether or not the events were connected and whether or not the children included the events as they were presented in the story. The criteria for how closely the art and discussion session followed the text was whether or not the children used the text and the events in the story as the focus of their Art Project Discussion.

The groups all varied slightly from the text during their Story Enactment or Art Project Discussion sessions. Some of the children included these variations in their retellings while the others did not. Following is a summary of how closely the groups followed the texts within the activities.

Table 6 --Extent to Which Text was Followed During Sessions

\begin{tabular}{lllll} 
Group & Stone Soup & Strega Nona & Blueberries for Sal & Sylvester \\
\hline 1 & closely & slight variation & closely & closely \\
2 & slight variation & closely & closely & closely \\
3 & closely & closely & closely & closely \\
4 & closely & slight variation & variation & variation \\
\hline
\end{tabular}

Despite at least one variation per group, the texts were for the most part followed closely during the Story Enactment and Art Project Discussion activities. The groups varied from the text slightly during the Story Enactments twice. Group 1 and Group 4 both included the same plausible event, not stated in the story, by having Strega Nona and 
Big Anthony invite friends to lunch. This made it possible for all of the children in Group 1 and Group 4 to participate. This variation affected one out of six children's retellings. Child 12 included in her retelling how someone was invited over for dinner and used a number of sentences to discuss this information.

The text was not followed closely three times during the Art Project Discussions. One time was during Group 2's Art Project Discussion of Stone Soup, where one child drew a picture of an angel and another included fireworks. The children discussed these pictures; this slight variation was not reflected in any of the children's retellings. The other two times that the text was not followed closely was during both of Group 4's Art Project Discussions. During Blueberries for Sal, Child 10 went off on a tangent about how it was snowing and they were dancing in the snow. The other children picked up on how it was snowing and added this into their discussion and into their drawings. During Sylvester and the Magic Pebble, Child 10 spent a lot of time discussing how the family was painting their house. This information was not part of the story. None of the children included the facts from these discussions in their retellings, however, Child 10 and Child 12' s retellings were not very focused. This may be because this group's discussions of the stories were also not focused.

During the other eleven activity sessions, the children followed the text closely by including many events from the story, however, the percentage of events included in each child's retelling varied from child to child.

During the analysis, it was found that although in both types of activities the children were communicating with each other, what they were saying and the purposes of interactions was very different. During the Story Enactment the discussions focused on what to say, how to act, or what was happening during the enactment. For example, during Group 2's Story Enactment of Blueberries for Sal, the children discussed who they wanted to be, where the props should go and what their characters were doing. They also 
said the lines for their characters. All this was very different from the discussions during the art project which focused on what to draw, what colors to use, and what happened in the story. For example, during Group 2's Art Project Discussion of Stone Soup, the children discussed which picture to draw, what they were inchuding in their pictures, the markers, and events from the story. The discussions were more descriptive, and the children did not need to negotiate. Although the children did talk about the story events in the Art Project Discussion, they also talked about events less connected to the story itself, such as what and how to draw.

Despite the fact that there were few deviations from the text, there were observed differences in what the children chose to inchude during the activities. There was more reference to the story grammar components and event sequence in the Story Enactment than in the Art Project Discussion. In Art Project Discussion, there appeared to be more character and object descriptions than in Story Enactment. A good comparison for this difference comes from looking at Group 3's Story Enactment of Sylvester and the Magic Pebble versus their Art Project Discussion of Stone Soup. At the beginning of the Story Enactment of Sylvester and the Magic Pebble, Child 7 took the book and set up the scene, "This will be the little table. Now we just need one chair. The dad's sitting in the chair." After setting up the scene, the children began acting out the story by following the book. Some examples of lines that include story grammar components and that follow the events in sequence are as follows:

Child 9 (Sylvester) -- Picks up the rock and wishes it would stop raining.

Child 7: Here comes the lion. Come on out. (Directions to Child 8.)

Child 9: I wish I were a rock.

Child 7: 9, You're still the rock and you're sleeping inside the rock. 
Child 7: Now I have to be the neighbor. (Child 7 becomes a neighbor looking for Sylvester.)

In contrast, during the Art Project Discussion of Stone Soup the children discuss what they are drawing and isolated events from the story. Some examples of the children's comments are as follows:

Child 8: Cabbages, cabbages. You know we should color before we glue.

Child 7: Im making red tomatoes.

Child 8: Im making that. (Pointing to a picture in the book.)

Child 9: You could make the window.

Child 7: Now I'm gonna make them all dancing over here.

Child 9: That can be the fireplace.

Child 7: I'm making a person having a feast.

Child 8: Maybe Ill make some people.

Child 7: Now I'll make something different. Them dancing over here.

Child 8: Ill make everything in my soup.

Child 7: On this side they're gonna be sleeping. On this side they're gonna be awake.

Child 9: I'm putting red cause chimneys are red.

As you can see from these excerpts, the focus of what the children talked about during the two activities was very different. For the most part, there was little variation from the text in the Story Enactments and all major story grammar components were included in order. There was also little variation from the text in the Art Project Discussions, but while many story grammar components were included, they were done so in an isolated and not always organized fashion and some components were deleted. 
How much investigator support was required during the enactment, discussions, and retellings?

The amount of support needed depended on the group as well as the activity type. For example, Group 4 needed a high level of support during both activities while Group 2 needed very little support during the two activities. Group 3 needed more support during their Story Enactments than during their Art Project Discussions. While Group 1 needed more support during their Art Project Discussions than during their Story Enactments.

The amount of support required by each child also varied. Table 8 shows just how much support each child needed during the two activities (see page 27). In retrospect the amount of support each child needed during the sessions was compared with subsequent performance on comprehension and retelling. Thus, in addition to analyzing how much support each child needed, their scores on the measures of recall, comprehension, and events included (see Appendix C) were given overall ratings of excellent (E), good (G), fair (F), and poor (P), based on standard deviations from the mean and defined in Table 7.

Table 7 - Ratings for Measures of Recall, Comprehension and Events

\begin{tabular}{lll}
\hline & Recall/Comprehension & Events \\
\hline Poor (P) & $<8$ & $<17$ \\
Fair (F) & $9-13$ & $17-28$ \\
Good (G) & $14-18$ & $29-40$ \\
Excellent (E) & $19+$ & $40+$ \\
\hline
\end{tabular}

The above ratings were used to determine the children's performance on the retelling and comprehension measures and this was then compared to the amount of support each child needed during the activities. 
Table 8 --Comparison of Support During Telling

with Retelling and Comprehension Performance

Story Enactment $\quad$ Art Project Discussion

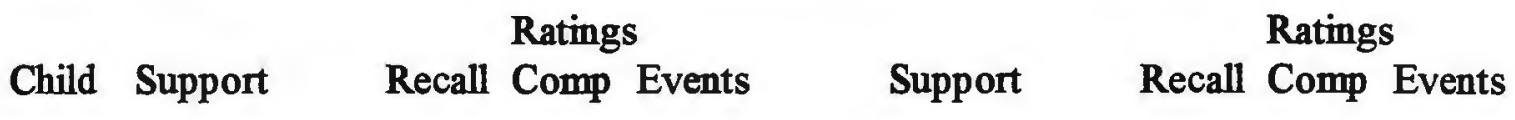

\begin{tabular}{lllllllll}
\hline 1 & medium high & P & G & P & medium high & P & F & P \\
2 & high & F & E & F & high & G & G & G \\
3 & low & E & E & G & medium & G & G & E \\
4 & low & E & E & G & low & E & G & G \\
5 & low & E & E & E & low & E & G & E \\
6 & low & G & G & G & low & G & G & G \\
7 & low medium & E & E & E & low & E & E & E \\
8 & high & F & P & F & high & P & P & P \\
9 & low medium & G & E & F & low & G & G & F \\
10 & high & F & F & P & high & P & G & P \\
11 & high & P & G & F & high & P & G & F \\
12 & high & P & P & P & high & F & P & P \\
& & & & & & & & \\
\hline
\end{tabular}

As can be seen from the table, the children who rated in the fair to poor range usually were the children who needed a high amount of investigator support during the session. The children who rated in the good to excellent range were usually the children who needed little investigator support during the activities. The relationship between amount of support needed during the activities and subsequent performance ratings on recall, comprehension, and number of events included was consistent across children. In other words, the amount of support needed was not affected by whether the activity was the Story Enactment or the Art Project Discussion. The one noticeable exception was Child 2, who needed a lot of support during the activities but rated excellent on measures of comprehension and rated good on recall and events during the Art Project Discussion condition. This may be because she was a shy and reserved child who may not have 
become very involved in the Story Enactment or Art Project Discussion because of her personality, but listened to the other children and picked up the information necessary to do well on the measures of comprehension and recall.

Although there were no clear differences in the amount of support needed between Story Enactment and Art Project Discussion, there were differences noted in the types of support needed. The type of investigator support needed during the Story Enactment included referring children to the book, narrating, and directing the children's actions. The investigator support needed during the Art Project Discussion included asking about and commenting on the children's pictures, commenting on events in the story, and referring them to the book.

Examples of these differences can be seen from comparing investigator comments during Group 4's Story Enactment of Strega Nona to their Art Project Discussion of Blueberries for Sal, remembering that Group 4 needed a lot of support during both the activities. During Strega Nona, the investigator helped the children decide what characters to be, "Who wants to be who?" and "Child 12, do you want to be a townperson with me?" She directed the children to set up the scene and then needed to tell Child 12 and Child 10 what they should be doing. The investigator used the book to narrate this story and to tell the children what to do. This group was the one where pauses and leading questions did not help the group to act out the story. The children would just stand there and wait until the investigator gave them a direction about what to do. In contrast, the investigator's comments during the Art Project Discussion of Blueberries for Sal focused on commenting on the children's pictures and on the story. Examples of investigator comments and questions are as follows:

Look through the book and decide what you want to draw.

With Little Sal eating blueberries?

[Child 10], who is this? 
What else can we make in the story?

[Child 10] has Little Sal and she's throwing blueberries up in the air.

I don't remember snow in the story.

Oh, I see why you think it's snowing because the pictures are black and white. I think it's just the way they make the pictures. I don't think it's snow.

What else can we draw about?

Good. Let's look through the book.

The ducks are flying that's great.

Oh she's too far away to hold her hand. That's okay.

Does anyone want to draw about the bears?

Let's listen to [Child 10] tell about her picture.

Good. Why don't you tell us about yours?

The types of support needed during the two activities was different. The investigator played a different role. During the Story Enactment, she focused on narrating and directing the children while during the Art Project Discussion she focused on getting the children to discuss their pictures and the story.

In addition to these differences in support, there were also differences in the amount and types of redirection needed. Redirection during the Story Enactment included refocusing the children on the characters they were playing by suggesting lines and telling the children what his/her character was supposed to be doing. During the Art Project Discussion redirection involved getting the children back to discussing their pictures and the book by commenting on what they were doing or the events in the book. Child 1 , and the two groups without a clear leader (Group 2 and Group 4), needed redirection. Child 1 needed to be redirected to continue to stay in character during the Story Enactment. Group 2, especially Child 4, and Group 4 needed to be redirected during both activities for 
different reasons. During both types of activities, Group 2 made tangential comments and discussed them. Group 4 had to be redirected because they could not remember the events or talk about how the characters felt. Group 3, and the other children in Group 1, did not need to be redirected. They were able to stay focused on the story during the Story Enactment as well as during the Art Project Discussion.

What were some individual differences among the children?

In addition to the questions answered, observations arose about individual differences among children. Despite the fact that all the children were enthusiastic participants and had good attention during the story reading and during the activity sessions, the manner in which the children interacted and their focus of attention during their retellings varied. Following are notable differences among the children. See Appendix $\mathrm{C}$ for individual child results and Appendix E for individual child retellings.

Child 2 became so involved in drawing her picture that she didn't participate in the discussion. She appeared to like the art project better than the Story Enactment and actually did better on the measures for the Art Project Discussion.

Child 3 expressed concern about his performance during the activity session. During Stone Soup he stated, "This is a hard one to remember." and during the Art Project Discussion of Sylvester and the Magic Pebble he mentioned, "I forgot a little parts of it." His ratings were all in the good to excellent range, but he was also very aware of the fact that he needed to remember as much of the story as possible.

Child 4 experienced the Story Enactment first and loved it. She couldn't resist being dramatic during all parts of the session, including the story readings. She generalized acting to the Art Project Discussion by giving voices to the characters she was drawing and had them interact during the Art Project Discussion. Child 4 was one of the 
children who kept asking to act out stories again after the project was completed. Although she enjoyed the Enactments, Child 4's ratings were very close for all measures on Story Enactment and Art Project Discussions.

Child 6 integrated new information into his retelling. While listening to the story Strega Nona, he asked what a wart was. The teacher gave him a defimition and this definition appeared in his retelling. He also showed an understanding of the word 'memory' because when Child 4 asked to look at her page during the discussion of Strega Nona, he informed her, "You can think of it in your mind. I don't even need to look at it."

Child 7 attempted humor with Child 8 about what he was drawing. Child 8 had drawn some soldiers sleeping and then stated, "Maybe Ill make some people." Child 7 then stated, "Make sure you make quiet people cause the soldiers are sleeping." Child 7 did an excellent job on her first three retellings and then did poorly on her fourth and final one for Sylvester and the Magic Pebble. This is interesting because this was one story she was very involved in, taking on the role of director during the Story Enactment. One factor may have been that the session took place at the end of the day and by the retelling phase she may have been tired.

Child 8 was the child identified with the ear infection. He needed a lot of support during the sessions and his retellings were all unorganized. Child 8 made a connection between the Art Project Discussion of Strega Nona and his retelling. He used the term "grumbly" during the discussion and this word appeared in his retelling.

Child 10's pictures and discussions during the Art Project Discussion were often unrelated to the book. In turn, her retellings often included some information that was not in the stories. She enjoyed the Story Enactments and followed the book more closely than during the Art Project Discussions. Child 10's Story Enactment retellings were slightly more organized than her Art Project Discussion retellings. This may be because she was a 
more willing participant in the acting or because the Story Enactment made it easier for her to organize her thoughts.

Child 11 had trouble staying focused on the task at hand especially during the Art Project Discussions. This may be because the structure during the Story Enactment provides more support than the structure during the Art Project Discussions. It is also interesting to note that Child 11 used picture description to begin his retellings after the Art Project Discussions. He needed extra support to get him to understand exactly what the teacher was looking for.

Child 12 had trouble with both the art activity and the acting activity. She needed a lot of support during all the sessions. Child 12 needed to be redirected to listen to the stories while they were being read. This difficulty in listening may have contributed to her difficulty with the retellings and comprehension questions. Child 12 also invented her own stories during both retellings of enacted stories. She may not have understood exactly what she was expected to do.

Differences among children and differences in the roles they assumed were observed. These differences among the children helped to create the dynamics of the individual groups. This in turn created four different groups, each having its own distinct flavor.

Summary of Results

Although there were no quantitative differences found between the Story Enactment and the Art Project Discussion activities, some qualitative differences were noted. These differences are summarized below.

- The children only expressed gender concerns during the Story Enactment sessions and 
only three children expressed any type of concern about choosing a role of the opposite gender.

- Differences were noted in the types of social roles the children assumed, as well as, in how the groups interacted during the two activities. During the Story Enactment the children worked together to create a play and group negotiations were observed.

During the Art Project Discussion, the children created their own pictures and tended to work more independently.

- Differences were also noted in the way the children communicated. During the Story Enactment, the discussions focused on what to say, how to act, and the story's events. This was different from the Art Project Discussions which focused on what and how to draw. Although reference to events also occurred they were done so in an isolated and not always organized fashion.

- The amount of support needed was different for each group and each child but was usually consistent across activities. During the Story Enactment, the investigator supported the children by referring them to the book, narrating, and directing the children's actions. During the Art Project Discussion, the investigator supported the children by asking about and commenting on the children's pictures to, commenting on events in the story, and referring them to the book. 


\section{CHAPTER IV}

\section{DISCUSSION}

Combining Art and Discussion

In Pellegrini and Galda's (1982) study, enactments were found to be a more effective follow-up activity to facilitate comprehension than discussions which were more effective than art projects. The present study combined the art project with the discussion and showed that joining these activities made them just as effective as the Story Enactment. Thus, both Story Enactments and Art Project Discussions are effective activities and both have utility.

Despite comparable effectiveness on comprehension and recall, the Story Enactment and Art Project Discussion may stimulate different types of knowledge and skills. For example, Story Enactments include the major events in a more organized fashion and allow the children to re-see the story events in sequence. On the other hand, Art Project Discussions allow the teacher to focus the discussions on the story events that she wants the children to remember or the ones that she feels are important to the children's understanding of the story. Having two effective types of activities that stimulate different types of skills gives teachers and speech language pathologists a choice of activities for facilitating comprehension.

Differences between activities

Despite the fact that Story Enactments and Art Project Discussions were both effective, many differences emerged that a teacher or speech language pathologist may 
consider in deciding which activity to use and when. Differences can be found in the amount of support needed, the way the children communicate, and the social roles the children take on.

The nature of teacher support needed is different for the two activities. During the Story Enactment the teacher's role is directing the actions and helping the children connect the enactment to the story. The Story Enactment is more organized along a story structure framework, so a capable child could use the book as a guideline to lead his or her group in enacting the story. During the Art Project Discussion, the teacher's role is helping the children to discuss objects, characters, and events. The teacher needs to keep the children focused on the story and not on the project during the art activity. This type of activity would not be as successful without a teacher present to keep the children on task because it is less organized and relevant to the story lines than the Story Enactment.

The way children communicate during the activities is also different. Since the activities are structured differently, this might be expected. During the Story Enactment, the children use the text to recreate their version of the story so the discussion focuses on actions and the "here and now". The children talk about what to say, how to act and what is happening during the enactment. The children really need to work together to create the play so it is necessary for group negotiations to take place. The way the children communicate is more organized and follows the events in the story closely during the Story Enactment. This is different than during the Art Project Discussions, where the children create pictures and discuss the story so the discussion focuses on isolated events and pictures. The children can discuss what they are drawing, what they are including in their pictures, the markers, and isolated events from the story. In this case, group negotiations are not as necessary. During the Art Project Discussions, events are discussed in an isolated manner without much organization. These differences become important when trying to decide which activity to use. 
The children's social roles are also different and are important in a teacher's selecting either Story Enactment or Art Project Discussion. The social roles that emerged during this project inchuded leaders, helpers, participants, and followers. During the Story Enactment, social roles were very important because they helped the children follow the story and progress from one event to the next when there were leaders or co-equal competent participants. The investigator did not need to provide overall organization nor ensure that the sequence of particular events was followed during the enactment. This can allow Story Enactment groups to function without a teacher present, providing there is an effective child leader. For example, during this study the three groups where a leader or co-equal participants emerged required much less investigator support than the one group where no leader emerged. Thus, groups of competent children could be trained to function effectively without a teacher present. During the Art Project Discussions, the social roles the children played were not as important. The children created their own pictures and discussed the story. The children worked as individuals and, while it was necessary to the discussion that they interacted, the particular social roles they assumed did not appear to be important for group cohesion. During Art Project Discussions the teacher may play a more important role in keeping the children focused on the overall organization of the story.

\section{Teacher Decisions}

The differences between the two activities become important for a teacher deciding which activity to use. Which activity is chosen is dependent on what skills she or he wants the children to take from the story. Story Enactments are effective if a teacher desires an organized way to enhance the story and present the story grammar components. Story Enactments are also useful in helping children develop negotiation skills and to encourage leadership abilities. Story Enactments can be used successfully without a 
teacher present, if there is a capable child leader or aide. While Art Project Discussions are less organized than Story Enactments, they still have strong points. First, they give teachers another option for follow-up activities. They also allow the teacher the freedom to focus on one or two important story components and to discuss the feelings and emotions of certain characters. The teacher needs to be present during these sessions to help the children stay focused on the discussion of the story.

How much time the teacher has would also be a factor in deciding which activity to use because a Story Enactment could be run without the teacher present while the Art Project Discussion would require a teacher. Teacher personality also becomes a factor in choosing groups. If a teacher is looking for the groups to be more quiet and structured, a Story Enactment group might not be selected. In Story Enactments the children need to work together and they can't accomplish a good enactment while whispering. However, Art Project Discussions can be quieter and more controlled because they are more of a seat work activity. Some teachers also enjoy certain activities better. If a teacher really enjoys having his or her class create art work to take home, a very common practice, he or she would use Art Project Discussions as a follow-up activity. In this case, the children would be able to create their own projects and extend the story to increase comprehension.

\section{Creating Groups}

The differences between activities as well as the differences among children are important for a teacher or speech language pathologist who is faced with creating successful groups. The teacher needs to place her students in the appropriate type of group in order for the activities to be successful. A Story Enactment group would need a competent leader or co-equal participants to be successful. The teacher could allow this group to work independently provided they had a leader. She or he would need to make 
sure that leader was not too controlling. Child 3 was a good example of a competent leader. He was able to lead the other children without being too controlling. With a competent leader the other children in the group could fall into the roles of participant, helper, or follower, and the group could be successful. This combination also benefits the children with weaker skills without the teacher needing to be present which frees the teacher to be engaged with other children. The requirements for interaction can benefit children who have the potential to become successful leaders and the children with weaker skills. The teacher would also need to place children who are too controlling to be a successful leader into groups, a situation that did not arise in this study because the three children who had that potential randomly ended up in the same group (Group 2). Placing them in the same group may be one way to deal with children who tend to be too controlling. In this case the children's enactments were successful, and they didn't overpower each other because they all had strong opinions.

Art Project Discussion is less organized along a story structure dimension and thus may need to be set up differently from Story Enactment. If the teacher wanted the Art Project Discussion sessions to be productive, she or he may need to take a more active role than in a Story Enactment session with a competent child serving as a leader. In Art Project Discussion, the teacher would have to make sure the children focus on discussing the stories because otherwise it is too easy for the children to get off topic. In fact, a child leader would probably lead the children off task. The teacher's placement of children would depend on what skills she was focusing on during the Art Project Discussion. For instance, if she or he wanted to work on listening skills, she or he would place the children who needed to improve their listening in the same group and would be able to incorporate strategies that address this need. 
Gender Distinctions

It is clear that only during Story Enactment sessions did children express concerns about gender. This shows that gender issues are not likely to be evoked during Art Project Discussions. During art the children can discuss their pictures without regard to the gender of the characters while during the Story Enactment, role choices make gender distinctions an issue. It was also clear that gender distinctions were important to only a few of the children. Even at this early age, three children were aware of the differences in roles and were affected by these differences. What was interesting is that seven out of twelve children chose an opposite sex role without hesitation. They were not bothered by role distinctions so they choose the character they wanted to be without regard to gender. Five girls chose boy roles while only two boys chose girl roles. One reason for this may have been that there were more major boy roles than major girl roles and there were more stories with major boy roles. There were seven main characters that were boys and five that were girls. Two stories had more main boy characters, one story had an equal number of main boy and girl characters, and the fourth story had more main girl characters. It was more important for most of the children to play a major role rather than to have concerns about the gender of the character.

\section{Summary}

There are many differences between Story Enactment and Art Project Discussion activities. These differences are in the types of teacher support needed, the way the children communicate, the types of social roles, the presence of gender distinctions, organization, structure, and teacher involvement. These differences all become important factors in the teacher's decisions about the type of activity to use and the composition of grouping. Both activities increase comprehension so which activity a teacher chooses may depend upon what specifically she or he wants the children to be able to do. For 
example, Story Enactments may be better for learning story grammar components, for developing leadership abilities and for developing children's abilities to negotiate while Art Project Discussions may be better for focusing on main ideas, for discussing character's feelings, and for teaching listening. Since the current study showed that both activities effected comprehension and recall equally, selections of which activity to use stems from the qualitative differences that exist between the two activity types. 


\section{CHAPTER V}

\section{CONCLUSION}

It has been shown in previous studies that enhancing comprehension of stories is important. Previous studies have also shown that Story Enactment is an effective means of facilitating comprehension of stories for young children. The results of this study show that combining art and discussion (Art Project Discussions) was just as effective as Story Enactments and Art Project Discussions can be a successful means of facilitating comprehension in young children. Teachers and speech language pathologists can combine art and discussion to make an activity that is as effective as Story Enactment on some measures of recall and comprehension.

Although there were no quantitative differences found between the Story Enactment and the Art Project Discussion activities, some qualitative differences were noted. These differences, as well as some similarities, between the two activities are summarized below.

- The social roles established in the groups were consistent throughout the activities but the function of the roles changed. A Story Enactment was more successful if there was one, two or three competent participants or leaders. In contrast, the children's roles during the Art Project Discussion were not as important. Thus it would mean that when establishing a Story Enactment group it appeared to be more important to look at how the children interact to make the group successful than during a Art Project Discussion group. During an Art Project Discussion 
group, it is more important to group by the skills you want the children to focus on or by how well the children get along.

- Major differences were noted in what the children talked about while they were interacting. During the Story Enactments, the discussions focused on what to say, how to act, or what was happening during the enactment. The children had to work together to make decisions about characters and props so group negotiations were necessary. This was very different from the Art Project Discussions which focused on what to draw, what colors to use, and what happened in the story. The discussions were more descriptive, and the children didn't need to negotiate. These differences in communication may be important for a teacher deciding which activity to use to increase story comprehension.

- Gender concerns were only important during Story Enactments and relatively few children had concerns about gender when choosing their roles. Most chose roles with no concern for gender. For the most part, the gender of the characters wasn't important. What was important for the children is how active or fun the role was.

- The amount of support needed was related to the children's ratings on the measures of recall, comprehension, and events remembered. For the most part, children with a rating of good to excellent needed a low level of support and children with a rating of poor to fair needed a high level of support. This means that the children who needed less support usually had a good understanding of the story and were able to function without as much teacher support and therefore, tended to make good peer group leaders.

- Finally, the children's comments and attitude about both sessions were overwhelmingly positive. The children enjoyed both activities, which is likely to increase the benefits of these activities because children learn more when they are interested and involved in an activity. 
The results of this project show that combining an Art Project with a Discussion can be as effective as Story Enactment, and established method for facilitating story comprehension and recall in young children. There were qualitative differences suggesting that in some instances one approach may be selected over the other to facilitate a specific type of skill or interaction. The effectiveness of the combined Art Project Discussion method provides teachers with another method to use. The qualitative differences between the Story Enactment and the Art Project Discussion activities come into play when teachers and speech language therapists choose which activity to use to facilitate story comprehension and recall in young children. 


\section{REFERENCES}

Beck, Isabel L and McKeown, Margaret G. (1981). Developing Questions That Promote Comprehension: The Story Map. Language Arts. 58(8):913-918.

Billingsley, Bonnie and Ferro-Almeida, Susan C. (1993). Strategies to Facilitate Reading Comprehension in Students with Learning Disabilities. Reading and Writing Quarterly. 9:263-278.

Feldman, Jean (1991). A Survival Guide for the Preschool Teacher. The Center for Applied Research in Education. New York

Hoggan, K and Strong, C. (1994). The Magic of "Once Upon a Time": Narrative Teaching Strategies. Language, Speech, and Hearing Services in Schools. 25,April: 76-89.

Pellegrini, A.D. and Galda, Lee (1982) The Effects of Thematic-Fantasy Play Training on the Development of Children's Story Comprehension. American Educational Research Journal. 19,3: 443-452.

Saltz, Eli and Johnson, James (1974). Training for thematic-fantasy play in culturally disadvantaged children: Preliminary results. Journal of Educational Psychology. 66, 623-630.

Pellegrini, A.D. (1984). Identifying Causal Elements in the Thematic-Fantasy Play Paradigm. American Educational Research Journal. 21(3):691-701.

Silvern, Steven B., Taylor, Williamson, Surbeck, and Kelly (1986). Young Children's Story Recall as a Product of Play, Story Familiarity, and Adult Intervention. Merrill-Palmer Quarterly. 32,1: 73-86.

Knipping, Nancy Y. (1993) Let Drama Help Young Authors "Re-See" Their Stories. Language Arts. 70, January: 45-50.

Martinez, Miriam (1993) Motivating dramatic story reenactments. The Reading Teacher. 46,8: 682688.

Herr, Judy and Libby, Yvonne (1990). Creative Resources of the Early Childhood Classroom. Delmar Publishers, Inc. Printed in the United States of America.

Milliken, Linda (1992) Literature Patterns. Edupress, CA

Swanson, Lou. (1994). Changes--How Our Nursery School Replaced Adult-Directed Art Projects With Child Directed Experiences and Changed to an Accredited, Child-Sensitive, Developmentally Appropriate School. Young Children. May: 69-73.

Bookbinder, J. (1975). Art and Reading. Language Arts. 52(6): 783-785, 796.

Harp, Bill (1987). When the Principal Asks: "Why are your kids doing art during reading time?". The Reading Teacher. 41,3: 346-347.

Macey (1978) Combining Word Recognition with Art. The Reading Teacher. 32, Oct:64-65. 
Watson (1994). Enhancing Literacy. Language, Speech, and Hearing Services in Schools. 25, July. 136-145.

Goldenberg, Claude (1992/1993) Instructional conversations: Promoting Comprehension through discussion. The Reading Teacher. 46,4: 316-325.

Brown, Marcia (1947) Stone Soup. Macmillan Publishing Company. New York

DePaola, Tomie (1975) Strega Nona. Half Moon Books, An Imprint of Simon \& Schuster. New York.

McCloskey, Robert (1948) Blueberries for Sal, Puffin Books. New York.

Steig, William (1969) Sylvester and the Magic Pebble. Simon and Schuster books for Young Readers, Divisions or Simon \& Schuster, Inc. New York.

Glenn, C. and Stein, N. (1980) Syntactic structures and real world themes in stories generated by children (Technical Report). Urbana: University of Illinois Center for the Study of Reading.

Fry's Readability Graph (1969) Maginnis, George. The Reading Graph and Informal Reading Inventories. The Reading Teacher. 22, March: 518.

Maynard, John. Model Questions and Key Words to Use in Developing Questions. Based on Bloom's Taxonomy. Developed and Expanded. Pamona, California.

Murrow and Smith (1990). Group Size and Story Reading. Reading Research Quarterly. XX:213-231.

Heath, Shirley Brice (1983). Ways with Words. Cambridge University Press. New York 


\section{Retelling Score Sheet}

Adapted from Murrow and Smith's (1990) scoring of children's free recall

Date:

Teacher:

Subject:

Story:

Treatment:

Child receives 1 point for each of the following elements included in retelling:

Presents introduction:

Main Character:

Other Characters:

Setting:

Theme:

Resolution:

Ending:

The child receives 1 point for telling $0-50 \%$ of the plot and 2 points for telling $50-100 \%$ of the plot.

Plot - \# events named

total \# events

The child receives 2 points for:

Proper order:

Interpretive Statements:

Total:

John Maynard's expansion of Bloom' Taxonomy.

The types of questions and point values are as follows:

Type:

Number of questions: Points per question:

Knowledge (Eliciting factual answers) Comprehension (Translating, interpreting) Application (To situations that are new) Analysis (Breaking down into parts)

3
1

2

3

3 


\section{APPENDIX B}

The principal investigator lead each session which involved reading the story and then either enacting the story or making and discussing a story related art project. These sessions took place in the children's natural school environment. Each group listened to the stimulus target story first. The title, author and the reason to read the story was introduced. "Today, we are going to listen to the story and then we will (act it out or do an art project and discuss it). I want you all to listen closely to the story so that you can tell it to another teacher when we are done." The story was then read exactly as it is written with pauses and expression (about 10 minutes). Questions and comments were not asked or made during the story by the investigator. If a child commented or asked a questions, the investigator responded naturally by either acknowledging the comment or by answering the question. After the story was completed the children were then introduced to their follow-up activity:

Activity A - Story Enactment (approximately 15-25 minutes)

The Story Enactment activity followed the following format:

" Today, we are going to act out the story we just heard. You will be able to use the book to help you act out the story." "The characters in the book are ." "Let's pick out who we are going to be for our play." The investigator followed the children's lead when choosing the characters. She used pauses to give the children the opportunity to pick out who they want to be. If this did not happen then she asked the children, "Who wants to be ?". If more than one child chose a character then the investigator suggested that: "We can put names in a hat to choose the character." The props were introduced and the children helped the investigator choose where the props will go. "Let's see, where should we put the to set up for our play?" The investigator then paused to allow the children time to set up the stage. If this did not happen then the investigator offered suggestions. She then helped the children start the story. "How does 
this story begin?" The investigator paused to allow the children time to respond. "Let's go to the book to see if we are right." The investigator played the role of narrator/stage manager. She held the book so the children could see the pictures (unless one of the children wanted to hold the book) and helped them follow the story. She let the children take the lead and offered suggestions when the children became stuck or got off track. She gave the children time to make decisions for themselves and intervened when they appeared to be stuck. The investigator helped the children get unstuck by suggesting lines, reminding the children of the problem or feelings of the characters, directing actions, showing pictures and by making appropriate comments. She also reminded the children of the main theme and how elements related to the overall theme.

Activity B - Art Project Discussion (approximately 15-25 minutes)

The Art Project Discussion Activity followed the following format:

"Today, we are going to do an art project about the story we just heard. You will be able to use the book to help you choose your art project." The investigator then directed the children on how to start the art project. Each art project involved the children gluing a cutout from the story on their paper. These cutouts were objects that appear frequently in the story. ( A pot for "Stone Soup" and "Strega Nona", a red pebble for "Sylvester and the Magic Pebble", and a blueberry bush and blueberries for "Blueberries for Sal".) After they glued that cutout on their paper they were told; "Let's look through the story to see which parts we want to draw in our pictures. Everyone can choose a different picture so really think about what you want to do before beginning your picture." "I'll put the book here (in a prominent place) so you can look at it to help you." The investigator paused to allow the children time to start going through the book. If the children did not start looking through the book or did not start discussing the story, the she got them started by showing them pictures and by making comments about the story. The investigator followed the children's lead for the discussion. If they started talking about the story while doing their 
activity she did not interfere and only made natural comments. If the children did not make any comments or did not discuss the story then the investigator lead them by making comments such as "I like the part when so and so did this." and "Does anyone want to look through the book to get more ideas about what to draw?". Once again the she did not intervene unless she had too. The investigator's comments include expanding the children's utterances, repeating what the child say and acknowledging comments in a natural way. 


\section{APPENDIX C}

Child 1

Story:

Treatment:

T-units:

Words:

Recall points:

Comp points:

Events (\%):

Role in group:

Level of support:

Story Attention:

Activity Attention:

Redirection:

Organization of retelling:

Age: 5 yrs, 0 mo

\begin{tabular}{|c|c|c|c|}
\hline Stone Soup & Strega Nona & Blue4Sal & Sylvester \\
\hline Enactment & Enactment & \multicolumn{2}{|c|}{ Art/Discussion Art/Discussion } \\
\hline 14 & 22 & 20 & 27 \\
\hline 92 & 178 & 135 & 147 \\
\hline 3 & 2 & 5 & 2 \\
\hline 4 & 10 & 7 & 3 \\
\hline 17.9 & 13.0 & 18.9 & 9.3 \\
\hline follower & follower & follower & follower \\
\hline medium high & medium high & medium high & medium high \\
\hline poor & poor & good & good \\
\hline good & good & good & good \\
\hline $\begin{array}{l}\text { needed } \\
\text { poor to }\end{array}$ & $\begin{array}{l}\text { needed } \\
\text { poor }\end{array}$ & $\begin{array}{l}\text { needed } \\
\text { poor }\end{array}$ & $\begin{array}{l}\text { needed } \\
\text { poor }\end{array}$ \\
\hline
\end{tabular}

Child 2

Age: 6 yrs, 3 mo

Story:

Treatment:

T-units:

Stone Soup

Strega Nona Blue4Sal

Sylvester

Enactment

12

Words:

67

Recall points:

7

Comp points:

9.6

Events (\%):

23.1

Role in group:

follower

high

Story Attention:

good

Activity Attention:

Redirection:

good

Enactment

8

49

4

10

13.0

Art/Discussion Art/Discussion

9

57

6

118

not needed

good

\section{follower}

high

good

good

9

27

Organization of retelling:

not needed

good-short

\section{follower}

high

good

good

not needed

good
37.2

follower

high

good

good

not needed

good 
Child 3

Story:

Treatment:

T-units:

Words:

Recall points:

Comp points:

Events (\%):

Role in group:

Level of support:

Story Attention:

Activity Attention:

Redirection:

Organization of retelling:
M

Stone Soup
Enactment

19

69

11

9.6

43.6

leader

low

good

good

not needed

good

Age: 5 yrs, 5 mo

Strega Nona Blue4Sal Sylvester

Enactment Art/Discussion Art/Discussion

19

151

10

10

34.8

leader

low

good

good

not needed

good
24

206

10

9

56.8

participant

medium

good

good

not needed

good
18

108

8

10

30.2

participant

medium

good

good

not needed

good

Child 4

Age: 5 yrs, 1 mo

Story:

Treatment:

T-units:

Stone Soup

Strega Nona Blue4Sal

Sylvester

Art/Discussion Art/Discussion Enactment

Enactment

Words:

14

19

141

10

11

133

8

86

109

Recall points:

11

10

9

11

Comp points:

7.3

32.6

10

10

Events (\%):

30.8

24.3

32.6

Role in group

participant

Level of support: low

participant

participant

low

low

participant

Story Attention:

Activity Attention:

good

good

good

low

good

good

good

good

needed

needed

needed

good

good

good

good

needed

good 


\section{Child 5}

Story:

Treatment:

T-units:

Words:

Recall points:

Comp points:

Events (\%):

Role in group:

Level of support:

Story Attention:

Activity Attention:

Redirection:

Organization of retelling:

Age: 6 yrs, 0 mo

Stone Soup Strega Nona Bhe4Sal Sylvester Art/Discussion Art/DiscussionEnactment Enactment

18

172

11

7.6

48.7

participant

low

good

good

needed

good
33

334

10

10

52.2

participant

low

good

good

needed

good
21

172

11

11

51.3

participant

low good

good

not needed

good
17

176

10

10

44.2

participant

low

good

good

needed

good

Child 6

Age: 5 yrs, 11 mo

Story:

Treatment:

Stone Soup Strega Nona Blue4Sal

Sylvester Art/Discussion Art/Discussion Enactment

Enactment

T-units:

16

25

11

27

Words:

153

242

93

247

Recall points:

10

7

8

7

8

11

35.9

41.3

9

Events (\%):

participant participant

24.3

10

Role in group:

low

low

participant

low

41.9

Level of support:

good

good

good

participant

good

needed

good

good

needed

good

not needed

good

good

low

good

good

Organization of retelling: 
Child 7

Story:

Treatment:

T-units:

Words:

Recall points:

Comp points:

Events (\%):

Role in group:

Level of support:

Story Attention:

Activity Attention:

Redirection:

Organization of retelling:

Age: 6 yrs, 3 mo

Stone Soup Strega Nona Bhue4Sal Sylvester Art/Discussion Art/DiscussionEnactment Enactment

\section{7}

174

31

336

33

336

19

148

10

11

11

10

67.6

47.8

participant

low medium low medium

low

good

good

good

good

not needed

good low

good

good

not needed

good good

not needed

good good

not needed

good
Child 8

Story:

Treatment:

T-units:

Words:

Recall points:

Comp points:

Events (\%):

Role in group:

Level of support:

Story Attention:

Activity Attention:

Redirection:

Organization of retelling:
M

Age: 4 yrs, 7 mo
Stone Soup Strega Nona Blue4Sal Sylvester Art/Discussion Art/Discussion Enactment Enactment 21

135

27

131

3

2

20.5

follower

high

good

good

not needed

poor
13

104

7

2

16.2

follower

high

good

good

not needed

poor
18

137

3

5

18.6

follower

high

good good not needed poor 
Child 9

Story:

Treatment:

T-units:

Words:

Recall points:

Comp points:

Events (\%):

Role in group:

Level of support:

Story Attention:

Activity Attention:

Redirection:

Organization of retelling:

Age: 5 yrs, 0 mo

Stone Soup Strega Nona Blue4Sal Sylvester Art/DiscussionArt/DiscussionEnactment Enactment

12

10

9

21

63

8

10

25.6

103

7

58

10

130

9

8

19.6

participant

low

good

good

not needed

good

participant

low

good

good

10

21.6

10

32.6

participant participant

low medium low medium

good good

good

good

not needed

good

not needed

good

good
Child 10

Story:

Treatment:

T-units:

Words:

Recall points:

Comp points:

Events (\%):

Role in group:

Level of support:

Story Attention:

Activity Attention:

Redirection:

Organization of retelling:
F

Age: 4 yrs, 5 mo

Stone Soup Strega Nona Blue4Sal Sylvester

Enactment Enactment Art/Discussion Art/Discussion

12

42

6

7.3

15.4

follower

high

good

good

needed

poor to

medium
8

38

5

4

10.9

follower

high

good

good

needed

poor to

medium
11

49

3

9

13.5

follower

good

good

needed

poor high
65

5

6

14.0

follower

high

good

good

needed

poor 
Child 11

Story:

Treatment:

T-units:

Words:

Recall points:

Comp points:

Events (\%):

Role in group:

Level of support:

Story Attention:

Activity Attention:

Redirection:

Organization of retelling:
M

Age: 5 yrs, 1 mo

Stone Soup

Enactment

12

75

5

9

28.2

follower

high

good

good

needed

poor to

medium
14

91

5

7

21.6

follower

high

good

poor

needed

poor to

medium
Strega Nona Blue4Sal Sylvester

Enactment Art/Discussion Art/Discussion

13

65

1

5

17.4

follower

high

good

good

needed

poor
17

120

2

9

18.6

follower

high

good

good

needed

poor
Child 12

Story:

Treatment:

T-units:

Words:

Recall points:

Comp points:

Events (\%):

Role in group:

Level of support:

Story Attention:

Activity Attention:

Redirection:

Organization of retelling:
$\mathbf{F}$

Age: 5 yrs, 3 mo

Stone Soup Strega Nona Blue4Sal Sylvester

Enactment Enactment Art/DiscussionArt/Discussion

30

27

24

24

314

230

3

4

17.9

6.5

171

180

6

3

2

16.2

6

follower

follower

follower

11.6

high

high

follower

poor

poor

poor

needed

poor high

poor

high

poor

poor

needed

poor poor

needed

poor 


\section{APPENDIX D}

Group 1

Presentation 1

Stone Soup

Acting

I: Introduces story.

1: What's Stone Soup?

What it call? I forgot?

I: Stone Soup.

I: Reads story. --nothing to eat for 2 days.

3: Gulps

1: Im allergic.

I: Reads -- villagers hiding food.

1: Why they hiding their food?

2: They don't want the soldiers to eat the food.

I: Reads --entertaining King.

3: This is a hard one to remember.

I: Reads --night time.

1: Why is it night time for them?

I: Because its time to go to bed.

I: The End.

1: What are we going to next?

I: Act out the story.

1-bouncing in front of story and other children, tapping foot, needs refocusing.

2\&3- good attention throughout.

I: Introduces activity.

I: What characters can we be?

1: I know Minnie Mouse or Daffy Duck.

I: From the story. What characters can we be?

1: I wanna be little childrens.

I: Let's look at the characters. Who do we have?

1: Fll show you. (takes book and looks through it)

I: Do we have anyone who can be a soldier?

1: (to 3). You could be one cause you're a boy.

3: The person..... (internupted b 1)

1: I want to be this one (shows a picture)

I: Well I have some nice soldier hats for anyone who wants to be a soldier.

$2 \& 3$ not commenting.

I: Let's get started. Let's see I have some soldier hats.

1: (to 3) You could be one.

I: 3, would you like to be one?

3: Yes.

I: 2, would you like to be a soldier?

2: nods head.

Children get hats on. 
I: 1 , would you like to be a soldier too?

1: Yeah, I needa take my headband off.

Child one has trouble with hat.

Investigator directs children where to stand.

child 3 sits.

1: Not sit stand! Then she sits.

I: What do we need to do now?

1: I can't get my hat on.

I: Let's use the book to see what we need.

3: Stones.

I: Good thinking. Let's see...

1: Soup

I: Let's hide the stones.

Children walk over to get them and then each child hides a stone.

I: What else do we need?

1: Soup.

I: Soup.

1: And carrots.

I: Let's put all the vegetables over here.

Child 3 looking for other children's stones.

I: Well we have lots of vegetables.

3: Salt and Pepper.

I: Good, Let's put them over here.

1: I got salt. Can I do salt?

I: Well, let's first get everything ready okay?

1: uh huh (yes)

I: I think we might have to play villagers and soldiers at times, okay?

Children agree.

1: But who gonna be our villagers.

I: We'll all help out.

I: Let's start the story okay?

Investigator holds book : 3 soldiers walking down the street.

1: repeats.

Children just standing around.

I: And what's up with these soldiers?

3: 3 soldiers walking down the street and they are very hungry. The first soldier he saw a villager--visitor--village.

I: 3 , you can be the first soldier. What are you looking for?

3: A village.

1: $\Gamma m$ gonna be the last one.

I: A good dinner, you're hungry.

I: You are yawning. What are you looking for? (points to 2)

2: A bed.

3: And the last soldier... 
Investigator gives quite a bit of support.

Child 3 really helps to tell/act the story. Naming the places to hide the food.

Child 2 slowly hides food. Very quiet.

Child 1 runs around hiding food.

I: I11 be the villager. Come and ask me for food.

3: Asks for food.

Next villager.

3--directs child 2.

3--takes over as lead soldier. Quotes book to direct action.

2--follows along slowly.

1--very active focusing on actions. Doesn't say much but participates in actions.

I--directs on how to ask for food. Children find vegetables and cut them into the soup.

3--really takes over with retelling.

1--needs directions to speak. Very rough. Involved in actions.

2--participates in actions. Doesn't say much.

3--Starts setting the table while the other children are finishing the soup. Dishes out soup.

Children sit down to eat soup.

I: Now all our soup is done.

3: We can dance.

Children move chairs out of the way and dance.

Children get tired.

Investigator plays villager.

You can sleep at the Priest's house, the baker's house and the mayor's house.

Children sleep with blankets.

Children wake up and fold their blankets.

Villagers say good by and thank you.

1: What are we going to do next?

3-quiet at first takes charge of retelling.

1--willing to participate but does not have a good enough grasp on the story to be a leader.

2--quiet, just follows along.

More investigator support early on. Less as child 3 took over.

Group 1 Presentation 2 Strega Nona Acting

More comments at the beginning. Children appear more comfortable.

I--Introduces book and starts to read.

3: Is this story long?

That's a funny name for a book!

1: Strega Nona

1: Where the grandma witch?

3: Why do they call her grandma witch?

I: Let's read the story and find out.

1: What's a magic touch?

I: Let's read and see. 
I: Reads--beginning to overflow.

3: What does that mean?

End of story.

1: He's getting fat.

1: Are we gonna do what we did with the soldier?

I: Right.

Good attention $2 \& 3$.

Child 1 plays with hair moves around, needs redirection.

I: Introduces activity. Now let's see.. the people in the book. Do you remember them?

1: Im gonna be....

I: Who do you want to be? Tell me.

1: The one with the while .... Ill show you. (takes book)

I want to be this one.

I: You want to be a person in the town?

1: Yeah.

I: Okay.

I: I need someone to be Big Anthony and I need someone to be Strega Nona.

3: I'll be Strega Nona.

I: Okay. 2, will you be Big Anthony?

2: Okay.

1: $\operatorname{Im}$ the one with the white.

I: Fil hold the book and IIl help 1 be the townspeople.

3: How are you gonna make the spaghetti flow all over the town?

I: You'll see.

Investigator sets up characters.

I: What does Strega Nona do?

1: I'm glad Im not Strega Nona. Its a boy.

3: Fix warts, fix headaches.

Children need to be reminded to act the story out at the beginning.

3- cures 2's headache and cures 1's warts.

3 --She does work in the garden. Acts out working.

Puts sign up.

2: Big Anthony brings the sign to Strega Nona.

I: Act it out.

3--tries to help 2 act it out, telling her what to say.

1: Say don't touch that pot.

Investigator helps 2 with lines.

3 takes over with hiring. Telling Big Anthony what to do.

2-- washes dishes, milks goat.

3-- Makes spaghetti. Investigator helps with poem.

$1 \& 2$ watching the scene.

3 does kisses.

$2 \& 3$ eat supper and invites their neighbor over (1).

Children pretend to eat pasta. 
1: Yells--this is my plate.

Is asked to go easy.

2 cleans up everything. (Big Anthony)

3,1 and investigator help 2 tell her part.

3--tells his lines.

1: Tell him don't touch the pasta pot.

3-- goes over the mountain to see her friend.

2--needs direction to make pasta and invite townspeople to dinner.

3--helps her out with her lines.

All children eat pasta. 2 serves.

2--stops pasta.

3: He forgets the magic kisses.

Spread pasta around the room.

2--Big Anthony sits on pasta pot.

1--Uses rug patches for barricades.

3--comes back and stops pasta pot and blew kisses.

1--acts out getting mad at 2

3: Here's your fork eat all the pasta so I can sleep.

Big Anthony eats all the pasta.

1: Can we do another one?

I: (to 2) How do you feel?

2: Full

Group $1 \quad$ Presentation $3 \quad$ Blueberries For Sal Art

I--Introduces the story.

3: Sally picks blueberries.

I: Did you hear this story from others.

3: No, I have it at home.

1: She sure liked those blueberries.

I: That's right.

Children very attentive.

I--Introduces activity.

Children get tables and chairs ready.

I: The first thing we need to do is start off with..

3: Jars.

I: Well, every page has one thing---blueberry bushes.

3: Are we going to staple or glue them.

I: Glue and here it is.

1--playing with book.

Children glue bushes on quietly.

I: Next, we can put blueberries on. Show the children how to glue blueberries on. And children go about gluing.

I: After your blueberries are on you can start coloring. We have crayons and markers.

Children start gluing and coloring. 
I: While we are working on our pictures, we can talk about what we are doing and use the book to discuss the story.

Children are quiet.

I: 3, What are you making?

3: A blueberry.

I: 1 , which picture are you drawing?

1--shows picture.

I: Oh, the mom and Sal going down to the car.

3: This is the trunk of the tree.

I: Oh, I see.

Children are quiet.

I: 2, what are you going to draw? Would you like the book to help you decide?

1: Here you go (hands book over and child 2 starts looking.)

1: You know what? I making bushes.

2 opens to a page.

I: I is that what you're drawing? Good choice.

Children are quiet. 3 still gluing.

I: 2 is drawing the little bear and the mom. 1 is drawing the Mom and Sal walking down the hill.

3: Im drawing this one. (points to the picture 1 is doing.)

I: Well, why don't you look at all the pictures and decide what to draw.

3: Okay,

1: This is part of the bushes.

Children quietly coloring. 3 looking through book.

3: Im gonna do this one.

I: That's a good choice too. Little Sal and the Big Bear.

Investigator goes over what everyone is drawing.

Children are still quiet.

I: Awesome branch 3. I like it. (to 2) Would you like to see your page?

1: Can I see my page just for one more minute.

I: shows page.

Marker talk

I: 3 Awesome blueberry tree. (to 2) 2 is making a beautiful mom. Do you need to see your picture 3.

3: Yeah.

Children quietly color.

I: What are you up to 2 ?

1 : Is that 2 's page?

I: Yes.

1: Okay, I was just wondering.

3: Can I see my page again?

I: After we are all done we are going to tell about our pictures.

1: But what can we tell 'em?

I: What you draw. 
1: That's a pretty dress there (pointing to 2's paper)

I: Oh 3 that's an awesome bear.

I: 1 what are you drawing now?

1: Im drawing blueberries.

Quiet.

1: Do we get stickers after these?

I: Yes, but let's concentrate on what we are doing.

I: Does anyone need to see their picture again?

1: Me. Look it.

I: That's nice.

I: 1 I think you're ready to start drawing people.

3: 1 I think you drew a lot more blueberries than I did.

I: That's okay.

I: 1 What color do you need for people?

1: Red.

Children quietly looking for markers.

Investigator holds up book throughout

I: 1 what are you drawing?

1: The baby.

I: You can take the book if you want to look at it.

2: I need to see my picture.

I: Take it and find the picture you want to draw.

Children color.

I: You need to look 3? Here you go.

1--grabs book to look.

2: I need my...

1: I like Sal and her mom cause $2 \& 3$ have a mixed one.

I: Are you drawing a bear 2?

1: The bear's mostly black. So you gotta get some black in there.

Children quietly color.

I--redirects child 1.

I: When you are all finished put your name on the back.

1: Done.

I: Put your name on the back.

I: 3 are you ready to tell about your picture? $1 \& 2$ you need to listen.

3: They got mixed up. I used lots of colors instead of black and white. Little Sal is um Little Sal and the Bear mother are standing up.

Silence.

I: 1 would you like to go next.

1: These are all the blueberries.

I: And what's happening?

1: This is part of the blueberry bush and this is the half sun. And here those are when that's him and the mommy and that guy and little... and these are the toys to go with him. I: 2 , why don't you go. Tell us about your picture. What did you draw about? 
2: When the bear is with the mom and she thought it was Little Sal.

I: Anything else.

2: No.

A lot of support needed to get the children to discuss.

The children put a lot of work into their pictures. And they all had turns looking through the book and at one another's pictures.

Group 1 Presentation 4 Sylvester and the Magic Pebble Art

I--Introduces story.

1-What story are we doing today?

Children attentive.

1: Can I see? That's the picture in the front!

I-Introduces activity.

Children set up tables and chairs.

I: First, we can take the book and decide which picture we want to do.

1: Which one do you want to do? This one or this one? (has book)

I--passes out paper.

3- Why are we gonna glue?

I: Well, there's one thing in almost all of the pictures what is it? (Holding red pebble.)

3: The pebble.

1: I'm doing this one.

I: Which one? Oh the first one where he has his magic pebble.

I: 3 you can hold it and look. (book)

Gives him time.

I: Which one are you doing 3 ?

3: That one.

I: Oh the one where he's holding the pebble. 2 , Which one are you doing?

2: I don't know.

I: Why don't you look through the book and decide?

2: This one (first page)

I: Did you look through the whole book to make a choice.

2: No

I: Why don't you do that?

2--looks through the book.

1--gluing on pebble.

3: Now I don't know what it looks like.

Child 2 chooses page 1 after looking through the book. Opens it up to that page and starts coloring.

Children are very quiet.

I: We can talk about what we are making.

1: Is she doing that one?

2: Yes.

3: Im drawing a black rock.

Child 1 tapping foot and moving around a lot but not saying much. 
1: This is part of the chair.

2: This is part of the table.

1: 3

I: 3 's doing a great job. What are you working on 1 ?

1: That's mommies. This is where the mom's chair is.

2: Was the dad sitting in it?

I: Was the dad sitting in the mom's chair. Is that what you said 2?

2: nods.

I: What is that 1 ?

1: This is the back of the dad's chair.

I: (to 3) Oh, that's a great Sylvester. Do you need to see your page?

3: Im making him pick up the rock.

I: Good choice.

1: She has a plate.

3: No she doesn't.

1: Right there.

I: Oh the plate is on the fire place.

I: That's a pretty table 2 .

1: That's very pretty 2 .

2: Thank you 1.

Talk about the thunder and lightening storm from the night before discussing personal stories about how loud it was and trees that were knocked down.

I: Do you think the storm from the story was that bad?

3: It lightened into the trees.

1: These are part of the rocks. They're inside the rock.

3: Im done with my picture.

I: Is there anything else you want to add?

2: You could make grass.

3: This is how you do grass. Look it I made grass --green and red make brown.

3: Im gonna make a whole pile of grass.

I: 3 Do you want to look through the book and see anything else you want to draw?

3: No.

I: 1, what are you making now?

1: The sun.

1: The sun is rising up.

I: That's a great picture of Sylvester, 3 .

I: I like the way we're working hard.

(looking at 3's picture) 2: Wow, look that grass is tall.

1: Is that grass?

3: Yes.

1: Why are you making so many grass.

3: Cause I want to.

2: I think I'll use the crayon since my table is all crayon.

I: Good choice. 
2: Im going to make the stones after I make Sylvester.

I: You can put your name on it when you are done.

1: You can use another green.

1: What are we doing after this.

3: Telling the story.

1: Telling the story?

3: I forgot a little parts of it.

I: That's okay. 3, why don't you tell about your picture.

3: They find the red pebble.

I: Could you tell us a little bit more?

3: There is grass growing over his head.

Silence.

I: So its when he finds the red pebble.

3: nods.

I: 1, why don't you tell us about your picture?

1: I did. The mommy she was worried about her son cause he been turned into a rock.

I: The mom's worried because her son is turned into a rock. Did she know he was a rock?

2\&3: No.

I: And what is your picture about? 2, why don't you tell us what your picture is about?

2: The first page.

I: Well, why don't you tell us what's happening on that page.

2: He's looking at the magic collection of his rocks.

I: Oh anything else?

2: No.

I: Okay, when you're done put your names on the back.

Group 2

Presentation 1

Blueberries for Sal Acting

4: What are we doing?

I: We are going to act out a story.

4: Are we gonna get costumes for it?

6: We can.

6: It's TV

5: We're on TV.

6: Awesome.

4: My dad has one of those.

5: My dad has one too.

5: I have that book.

4: Me too

6: I heard it before.

I: Okay, today $\Gamma m$ going to read the story

All: Blueberries for Sal.

5: She's Sal.

I--Continue introduction. 
4: Sal's a boys name too.

I: It can be. Reads story. Bear sat down and ate.

All: Blueberries.

5: Same, same, same.

Bird part.

4: Caw, caw, caw.

The End

Introduces activity.

4: I want to be Little Sal.

6: And you're gonna be the mother. (pointing to teacher)

5: Yeah, cause you're the biggest one.

I: Okay, let's decide whose going to be what.

6: I'm gonna be baby bear.

4: Im Little Sal.

I: 5 ?

5: The car?

I: Well let's see whose left?

4: The mother bear and

5: The mother Sal.

I: The mother bear and mother Sal.

6: No, you're gonna be mother Sal.

I: Okay, what could you do instead?

4: (in a teasing voice) You're gonna be 6's mother.

I: No, we're pretending so what could we do instead?

5: I don't know.

4: A daddy bear!

I: You're so smart 4.

5: Okay.

4: You have to stay home.

I: First, we need to put up the blueberry bushes. Now where would be a good spot for our bushes?

4\&5 (off camera) 5: over here 4: yeah.

6: over here.

I: Well it has to be on the camera so 6 has a good spot. Help me out.

4: I don't see any blueberries.

5: Where are they?

I: Well, we have the bush now what do we need.

All: Blueberries.

I: Now look over here.

All: Blueberries!

I: In a blueberry field blueberries are all over. Where can we put them?

5: On the top.

I: Where else?

4: Over here. 
6: On the bottom

5: on the sides.

I: Good everyone take blueberries and spread them out.

4: This is fun!

6: Its like snow flakes.

I: Spread them all out.

I: Let's see what's happening in the story first.

4: We need buckets.

I: We need buckets. Very good. Passes out buckets.

I: Now where can you all go?

5: Why do the bears need buckets?

I: You're right. They don't. If...

5: Cause he's a bear and Im a bear.

I: If you want you can use them to help you out because we're not going to really eat the berries.

4: Im gonna be a bear. Look it! You guys can do this (puts bucket in mouth).

I: Do you remember how they start the story?

6: I need the book to help.

5: I don't they went to the mountain.

4: I pick my blueberries (starts picking)

I: Okay, Im the mom and she's Sal and we're picking our blueberries.

5: Im with him and you're with her. 5\&6 make eating noises.

I: Okay, And you have to be telling what's happening.

4: Okay, mother (starts laughing).

I: You can do that we're acting.

4: I don't want to.

6: Gaga I'm eating berries.

I: What are you doing Little Sal?

4: I'm picking some blueberries for the last winter.

I: Good lets go up this hill (so the bears can come.

6: Im gonna go hunt for berries.

5: me too.

4: Im gonna go hunt for berries.

Children all picking.

4: I'm eating blueberries.

5: To Sal Rah. (children start interacting).

I: Okay, Little Bear's following me and Little Sal's following daddy bear.

4: No mother bear.

I: Okay, what do you hear?

5: Kurplink, kurplank.

Children just picking berries.

I: Okay, I guess we need the book to help us see what we are doing.

I: Little Sal is following.

5: Papa Bear. 
5: And then Little bear is following Mother Sal and then they go find their children.

I: First, he has to discover that Little Sal is following him.

5: I did already and ran away.

I \& 6 Act out finding out.

All children at once: I have to go find

4: No, Im eating them instead. Im taking the skin.

Know what. I. My uncle kills animals and I saw a dead bear rug. Two of them and I saw a dead moose head with eyes open and another one that was a deer.

I: Wow.

I: Little Sal let's go home now.

4: Okay.

5: We're gonna go under here.

6: Home into our cave. bye-bye.

Children got silly eating blueberries and playing with buckets. Investigator redirects to get them to clean up.

Group 2

Presentation 2

Sylvester and the Magic Pebble Acting

I: Okay.

5: What ears are those?

I: They're for our story "Sylvester and the Magic pebble".

5: Sylvester.

Children come over to get ears.

5: Im the king. (with ears)

4: No, I am.

5: No, I am.

Argue back and forth.

4: You're the king and $\mathrm{Im}$ the queen and we're getting married. Makes kissing noises.

Get children settled and Introduce story.

4: Are there a lot of picture?

4: Okay, teachers.

5: Im Sylvester.

6: No, I am.

4: I am.

I: I have a good idea. Let's listen to the story first and then decide who can be what character.

4: 6 is that one. (points to book cover)

6: No Im not.

I: 4, what did I just say? We need to listen.

I--reads story. First page.

4: Mmmmm Mmmm I love pebbles.

4: Those are kinds of stone rocks.

I: That's right.

4: Flinstones meet the Flinstones ....

I: Okay, are we ready to listen now. Sylvester likes to collect... 
All: pebbles.

6: Shiny ones.

I: studying pebbles.

5: Studying?

I: Holding it up and looking closely.

I: it ceased.

5: What does that mean?

I: It stopped in an instant, like that (snaps)

I: magic in the pebble.

4: Like Frosty the Snow man.

I: rain came down.

6: That's a wishing pebble.

4: I got hitted by lightening. (lies on floor)

I: Let's listen now.

I: lion crazy

6: Maybe he needs glasses.

Children become attentive.

I: dogs looking

5: They're kinda near him.

I: That's right (continues reading)

5: See that's him (points to the rock on the page)

I: See mom's upset.

4: They're not upset they're sad.

5: Dad's upset too.

I: alfalfa

4: Alfalfa?

6: From the movie.

The end.

Investigator starts to introduce activity.

4: Im being Sylvester.

5: No, Im being Sylvester.

4: no suh

5: Yes.

4 (to 6) Do you want to be Sylvester.

6: I'll be the pebble.

I: Well, Let's see what parts do we have: mom, dad, Sylvester - Anything else? Animals, lion.

All: Sylvester.

I: I'll put names in the hat to pick.

5: and you close your eyes and who ever gets their name on it is Sylvester.

6-- Gets to be Sylvester.

I: (to 4) Who do you want to be?

4: The mom.

I: (to 5) Do you want to be the dad? 
5: No the coyote.

I: Well you can e all the other animals, okay?

5: Yeah.

I: Now let's set up the room

I: Let's see what's first.

5: Im not in the group yet.

4: Im sitting in my favorite chair.

I: How can we set things up?

6: We need a table and a picture.

Children help set up room.

4: Sylvester you're supposed to be doing, looking at rocks at the table.

Sylvester gets set up.

4: This could be the silver one. The magic one.

I: Look what I have.

6: Magic pebble.

5: Not a real one.

5: Im still not in the picture.

4: Im sitting in my favorite chair.

I: Are we ready for action.

5: I need to get out of here.

I: Let's use the book. Can you tell me what's happening?

6: Sylvester is checking out his pebbles.।

4: I wish you'd do something else instead of collecting his pebbles.

I: Dad just smokes pipe and reads paper.

4: Here's your pipe.

5: I'm not in yet.

4: (to 6) Go out and find your magic pebble.

I: Let's get the outside ready.

4: I stay home and read my paper.

Sylvester looking at rock

5 pretends to be geese.

Rain noises.

I: What is Sylvester saying.

6: Uhhhh

4: I wish it would stop raining.

6: I wish it would stop raining.

4: and it did.

4: Go raining again.

6: I wish it would rain again and stop again.

4: Im looking at my paper.

5: Im out of the picture.

Walking home. Sees lion acts scared.

6: I wish I was a rock.

Lion goes around rock. 
5: I need glasses.

Shows he's going crazy.

Rock is sleeping.

4: I wish Sylvester would come home. Im worried about him

I: I wonder where he could be.

4: He never passed over dinner.

4: Let's go to sleep and in the morning time let's ask everyone.

Question animals

4: Have you seen Sylvester

5: No

4: Police have you seen him

5: No.

Children look.

5: I'm gone.

4--Sits on the rock. Sad.

Children get very silly acting out leaves and snow falling.

5: Wolf howls.

4: Let's sit on the rock.

Sits.

I: Let's get our picnic stuff ready.

Set picnic up.

5: But don't real sit on him.

Set up.

4: Don't move 6 or you'll wreck our picnic.

Put pebble on rock.

Sylvester turns back.

4--gets silly needs to be redirected.

4 hugs 6

Children get very silly hugging each other and the investigator.

I: What happens next?

Children hugging.

Group 2

Presentation 3

Stone Soup

Art

4 being the teacher and bossing the other two children.

I--Introduces story Stone Soup.

4: Oh that's the one 3 read.

I: That's right, Then we do an art project.

6: Are we gonna make stones and a soup and get fat, fat, fat.

I: Well, let's listen to the story to see what we are going to do.

Children get silly.

I: Relax ---refocuses children. Reads--nothing for 2 days.

4: Ouchy. Im starving, oh boy. (throws self on ground)

I--redirects 4.

Good listening after getting them settled. 
I: lighted torches.

6: What are torches?

I: (points them out) The fire.

All: "wow". Children are impresses where soldiers sleep.

5: Oh, the mayor's and priests house.

6: That's the God's. He can't sleep there.

The End.

Introduces activity.

Children help get room ready.

6: Three people 3 soldiers.

4: Actually there's 4 people.

6: 3 kids.

Children sit.

I: Let's think what we need first.

4: We're making a project.

I: The first thing we need is a pot.

5: Oh, I got it.

4: Can we make the little lid on the bottom?

6: Can we put fire on?

I: You can glue first or color.

All: Color.

I--Passes out stones and pots.

I: You can use the book to help you decide what to do.

4: Now next what do we need?

I: Well, look in the book to help you.

5: Carrots, potatoes, meat.

4: No (to book)

Discuss markers.

I: We can talk about what you are drawing and at the end we can discuss your pictures.

4: I drew a carrot. Now Im doing another one.

I: What are you doing 5.

5: Im drawing the fire.

6: Im putting the stones on top.

5: Me too. Just like a castle.

4: Im drawing a potato.

Marker discussion.

I: Let's look at the book to help us.

4: Im making some blueberries. Little ones.

5: Blueberries?

5: Looks like grass.

I: That's a good fire 5 .

6: Quotes commercial about cats 4 joins in.

I: Let's get back to the story.

4: I need glue now. 
5: Im putting stones right here.

4: I need paper towel.

Children fooling around.

I: Let's concentrate on our work and discuss our pictures.

5: Pitchers?

4: Pitcher's got a big butt.

I: I see $\mathbf{4}$ has carrots and?

4: Blueberries.

I: And 6 still has the fire.

6: Im gonna make a rock right there so I can push it up.

5: You can do whatever you want even scribble.

I: What are you drawing now 4 ?

4: The soldiers.

I: Good choice. What is your soldier doing?

Children get silly with markers. Need to be redirected.

5: Look I made squash.

4 needs to be calmed down.

5: Looking through book--Oh I need houses.

4: That's his chief hat with big arms.

I: You're putting in potatoes 6 .

4: Big brown beautiful potatoes.

5: And Tm making houses.

4: He's standing in the pot.

I: Nice hats 4.

4: Starts screaming. Ahhhh. He's in the fire.

4 gets sill needs redirecting.

I: What do you have a house in the background 4 ?

4: No, This is the roof.

I: Which one did you make 6? I know.

6--shows the priest's house.

4: $\operatorname{Im}$ doing this one.

Marker discussion.

4: Look at his blue pajamies.

I: Oh he's ready for bed.

Children discuss the day care's pot luck supper.

I: 4's drawing the table. What else can you draw?

5: The table with food.

5: Here's bowls.

5: there's a lot of people so I need a lot of bowls.

4: Im done.

I: Put your name on the back and then describe what you drew. 5 and 6 listen.

4: I made the pot with stew. And carrots. Actually, that's a cabbage, potatoes, blueberries. A man's leg stuck in the.... And here's somebody's pajama's with his beard. And here's some oranges and here's the windows and here's a big stone people. 
Now what can I do?

I: Now we can listen to 5 and 6's stories. Look through the book while you are waiting for them to finish up.

4: You guys want to look at the book.

5: What part are you looking at?

6: Im making some of my own up.

4 flips through book.

5: And one more thing. Im almost done.

4 works on her picture again.

5: Glue with brown makes orange.

I: Good thing to remember. Okay 5 , finish up your person.

5: Its not a person.

I: A bird? I don't remember that in the story.

6: That's okay you can make it up.

5: I'm making it up.

5: What do you think it is?

I: I thought it was a bird.

5: That's the wings, that's the head and she's coming down.

I: An angel?

5: Right actually the Holy Spirit.

4: There fireworks. Spread all over the place.

I: 6 Tell about your picture.

6: They're cooking the stew and the the three soldiers are cooking the stew and that's all.

I: What about that. You didn't tell about that.

6: I don't want to.

5: Is that the church?

6: Yeah.

I: Okay, You don't have to. Do you want to tell about yours 5?

5: They're having. They're throwing up those little things that you like do on party.

Cause they're having a party and that's the stew and that's the house. There's the smoke and the table and the angel in the sky and the rainbow.

Children are talkative. Need to be directed to discuss story.

Group 2

Presentation 4

Strega Nona

Art.

4: What book are we reading today?

I-- Introduces it.

5: Oh, I have this book at home.

4: Is it a good story?

5: I like the spaghetti part.

6: Don't tell us about it.

Start story. Good attention right off.

4: What are warts?

I: They're um like a cut on your hand.

4: A sore? 
I: Kind of.

Good attention.

I: Poor Big Anthony.

6: He's getting fat.

Introduces activity.

Children set up tables and chairs.

4: We can copy the cover.

I: You can copy the cover or look through the book. The first thing that's on every single page is

All: The pot.

I: You can glue first or color first.

4: Can you hold the book?

I: Fil get it in a minute

Talk about space. (the glue on the pot looks like starts)

I: 5 , which one are you doing?

5: Guess.

I: I see pasta coming out. You must be doing the town.

Children discuss gluing pasta on.

6: Im doing this one.

5: Im gonna make my own spaghetti.

Marker discussion.

5: Two food books in a row.

Quietly coloring.

4: Hey, can you get to my page?

6: You can think of it in your mind. I don't even need to look at it.

5: Me either.

I: Is that what the pasta is doing?

5: Its going all over in clumps.

4: My picture looks good.

I: What is it?

5: I know Big John or something.

T: Big Anthony.

5: Oh yeah.

Children quietly color. 4 very calm today.

I: Remember when you are done we tell each other about it.

5: Look at all the pasta.

I: Good.

6--tells about he is going to Boston this weekend.

I: Let's talk about the story.

6: I saw him go into Federal Express.

I: The guy in the story?

6: Yeah.

4: She's coming in now.

I: Who? 
4: The lady.

6: Strega Nona..

4: (in pretend voice) What are you doing to my house?

6: My angels going to Federal Express to pick up the package.

I: 5 , what are you doing?

5 doesn't answer.

6: Ahhh

I: That must be Big Anthony.

5: Maybe.

I: Are you going to make me guess? He has a hat let's look through the book.

5: Strega Ona.

6: We can make something that's not in the story.

I: I love that Strega Nona coming to save the day.

6: No.

I: 4's picture.

6: Is that an angel pasta?

I: Is he saying something?

5 is writing a bubble with words.

6: He's saying help.

4: Help me Egga Strona

6: No.

I: That must be Big Anthony.

5: Yeah.

6: Reading 5's. Help me I am going to.

5: Help me I am going.

I: I see 4 and 5 are putting a lot of work into it. What about you 6? You just have spaghetti.

6: I know.

I: Reading 5's Help me Im going to be wrapped up in the.

Children quietly working.

5: Help me I am going to be wrapped up in the spaghetti.

6: Mine is saying--Help me.

I: 4 , what are you writing?

4 doesn't answer.

5: Ahhh he's getting burned up in the fire.

4: How do you write "I"?

5: Three kisses cause $\mathrm{X}^{\prime}$ es are kisses.

4: How do you write "I am"?

5: "a-m"

I: What are you trying to write.

4: I am eating the spaghetti.

4 and 5 sound it out to write words.

I: helps 4 write words.

I: 4's all done. She's going to tell us about her picture. 
4: Okay, he's saying help me. She's coming in the door and wondering why he's saying help me cause spaghetti's coming out and here's the fire.

I: 5 , Why don't you tell about your picture.

5: That's the spaghetti and that's Strega Ona and he's saying Help me I'm going to be wrapped up in the spaghetti pot.

4: Bravo.

I: 6 tell us about your picture.

6: Strega Nona's blowing the three kisses to make the pot go shorter and that's all.

I: Okay.

Children more focused and quieter today.

$\begin{array}{llll}\text { Group } 3 & \text { Presentation } 1 & \text { Stone Soup }\end{array}$

I--Introduces story.

Reads 2 days.

9: Whoo!

Good listening. Quiet group.

Introduce art project.

8: We're gonna make a picture.

9: I can't do that.

I: Ill help you out.

I: What's the first thing?

9: They need stones.

I: Before that use the book.

9: Water.

We use the book.

All: The pot.

I: We can glue the pot on.

9: I was wondering what these things were.

I: Next, we need the main ingredient

9: Stones.

I: Good.

9: We glue them on the pot.

I: I need to get more glue.

9: I think we're gonna glue them on the pot. What do you think 7 ?

7: Im gluing them here.

9: Now all I need to glue on is this.

8: Maybe this one will come out.

I: Now we're going to draw in the soldiers, the town and the ingredient. Do you know what ingredient are?

7: There little things that you put on the side.

I: Good. We can use the book to decide what to draw.

8--Takes book and looks.

8: I'm looking for let me see what I'm looking for? This.

I: Oh the soldiers sleeping. 
8: Cabbages, cabbages. You know we should color before we glue.

9: tomatoes.

7: Im making red tomatoes.

9: Could we put in grapes?

I: Are they in the story? 9 laughs.

7: Im making tomatoes. Tomatoes and potatoes. They rhyme.

8: Im making that.

9: You could make the window.

8: Tm making the window.

7: Beef

9: Just put a cross on it.

I: 8 what soldier are you drawing.

8: This one.

I: Oh the one sleeping in the mayor's house.

7: Potatoes.

8: Red potatoes or mashed.

7: or they could be orange.

8: laughs.

7: Or brown.

9: Carrots.

8: $\operatorname{Im}$ trying to make the soldier.

I: That's a great one.

8: Now he's gonna have feet.

8: Now Im gonna make the blanky to cover his feet up.

9: I need the brown. Here we go.

I: What are you making 9 ?

9: The table.

7: Im gonna put the pot right here.

7: Tm making a chimney.

9: There.

I: What's that?

9: The table. I couldn't really do it.

7: Im gonna put the pot on the table.

8: I'm making a table.

9: Im trying to make a chair.

7: Just make a bench for them to sit at.

8: Im making a bench for them to sit and eat at.

I: Would it help us to look at that picture?

Gets book.

7: Now $\mathrm{Im}$ gonna make them all dancing over here.

9: That can be the fire place.

8: That's what $\Gamma \mathrm{m}$ looking for (page in book)

9: Hey that looks like pink flames coming out.

8: What else can I make? 
7: Im making a person having a feast.

I: Ohbh

8: Maybe I'll make some people.

7: Make sure you make quiet people cause the soldiers are sleeping.

8: But I already made a soldier sleeping.

7: They better be quiet people so they don't wake the soldier up.

I: That's right.

8: Now Im gonna make a pot.

I: What are you making 8 ?

8: I making I'm trying to make a pot.

7: There they are at the feast over here.

7: Now Ill make something different. Them dancing over here.

I: Dancing on one side feasting on the other.

8: Now Im making them sit.

7: 9 What are you doing?

9: Making the fire.

I: What else can we draw?

8: Im making this. (points to picture)

9: A blue chimney.

7: There's a girl now I just need a red boy.

9: How 'bout you make a Cinderella.

I: Let's do what's in the book.

8: Cinderella's not in this kinda book.

8: Ill make everything in my soup.

7: You can make anything. Here's the boiling water.

8: Maybe Ill make potatoes.

I: What a beautiful person dancing.

8: Where the boy?

7: Im making the boy.

I: What are you doing?

8: Im making the soup.

7: Now I need to make a dark sky.

8: Maybe Ill make a blue star.

I: (to 7) Why are you making a dark sky?

7: On this side they're gonna be sleeping on this side they're gonna be awake.

I: Good idea. Two parts to the picture.

8: I'm gonna make the sun.

9: Im putting red cause chimneys are red.

Marker discussion.

7: There's the bed.

More markers.

8: Now Ill try to make the sun.

7: Now I'm making a brown house.

I: Wow 7 you're making three houses. 
7: Now Im going to make the big red church.

8: Now Im done my sun.

9: The sky looks like crayons. Doesn't the sky look like crayons.

I: What else are you going to draw 9 ?

9: A table a little table.

I: Wow 7's picture looks almost finished.

8: Mines almost done.

I: When you're done put your name on the back.

7: Im done.

I: Put your name on the back then you can tell us about it.

I: 7 can tell us about her picture.

7: Well, this is the big house. This is the mayor's house, the baker's house and the church. And here they are in the daytime having a feast. Here's two little kids having the feast and grownups having the dancing. There's the pot boiling hot.

I: Excellent.

7: I didn't want to make a sun or anything cause its kinda dark.

I: Great is anyone else finished?

9: Im almost finished.

8: Im done.

I: Why don't you go?

8: This is the I can't think of the houses?

I: Well maybe 7 and 9 can help you.

7: I can. (pointing to her picture) Here's the mayor's house 8.

8: I made the mayor's,

7: The baker's.

8: I made the bakers.

7: the church.

8: I made the church.

I: Good what else did you make.

8: Well I made the peoples house and I drew a pot and I made soda in his cup.

Silence

I: Awesome, 9.

9: This is the fireplace and this is the chimmey and the pots boiling on the fire and there's someone standing on the bench eating food.

I: Great.

Group 3 Presentation 2 Strega Nona

Art

8: What story are we doing?

I: Good question.

Introduction.

9: My pop had to drop off 3 people.

I: Let's listen to the story.

Introduce activity.

8: Like the three soldiers. 
9: The three soldiers were easier.

Children help set room up.

I: Here's the book.

8: I have to make the pot first.

I: Just like stone soup we put on the glue.

Children glue.

8: This keeps going.

I: Til help you open it.

I: Next what can we put in the pasta pot.

8: Spaghetti.

I: Glue pasta on then we'll talk about what we are going to draw.

8: $T$ can you do this?

I: Can I hold the book open for you? Yes.

7: You're gonna make meatballs with your spaghetti?

7: Strega Nona has too much spaghetti in her pot.

9: Poor Anthony.

I: Let's look at the story.

7: Im making a meatball on top.

Children gluing pasta on.

I: Okay let's look at the story and talk about it.

7: I like the part where Anthony had to eat it all up.

8: I like this part.

I: You can draw that.

8: I like the part where Anthony's making the pasta.

8: The pot is bubbling.

8: Im gonna make this guy.

I: What part are you going to draw 9?

9: When all the spaghetti's going into town.

9: Spaghetti's going all away.

I: If you want to see your picture look through the book.

8: Im gonna make blue spaghetti.

9: That's a good picture 8.

7: Can I see the book?

7: Where is the part where he has to eat up all the spaghetti.

I: That's near the end.

7: There he is with an upside down smile.

I: An upside down smile so what is he doing?

7: He's unhappy.

9: Can I see? Holds book upside down.

I: What are you making?

9: I want to make spaghetti going all over town but I don't know how to draw the town.

I: Maybe your friends can help you.

7: Maybe you can make houses.

9: Ill try. 
8: Im drawing the spaghetti coming out.

\section{Looks through book.}

9: I just made a square house. Ill color in the triangle. And there's the sun rising up on the big mountain.

7: The man looks a little fat.

8: Whose fat?

I: Do you remember his name?

8: No.

I: Maybe the girls can help you.

Girls: Big Anthony.

7: He's getting a fat belly.

9: Im making a big mountain.

I: What are you drawing 7 ?

7: Strega Nona's house so she can sleep.

7: That's right she gets to sleep at the end.

9: Im making two mountains.

I: What are you doing 8 ?

8: Im drawing lots of houses.

9: They're good houses.

9: There's a mountain with the sun rising up.

7: Im making a little door.

8: I made a little door right here with one step.

7: Here's Strega Nona's steps and her bed.

9: Im making a bed.

7: Here's Strega Nona in bed. I don't have to make a face on Strega Nona cause she's sleeping.

8: She's sleeping in her bed room.

9: I made some glasses on her.

8: Im gonna make a bed.

7: Im gonna make some more spaghetti.

9: There Im coloring her sleeping on the door.

8: Im covering her feet so her feet won't be cold.

I: You're covering her feet.

8: Oh he doesn't have a hat I forgot to make one.

8: He's happy here.

I: Let's see where he's happy in the story. Right here where he's making pasta.

8: But now he's grumbly because she went to sleep. Now he's waking her up.

7: I'm making more spaghetti.

9: Going down town to someone's house. and up where she's sleeping.

I: Remember when you're done put your names on the back.

9: Its going up to her bed room.

Children put names on the back.

I: 8 would you like to tell us about your picture first. 
8: Well the spaghetti's going all over the place and its boiling and its going all over the place and the spaghetti's going all over the place. And he's grumbly because she's sleeping.

I: Anything else?

8: Well I made 2 houses.

I: Whose ready next?

9: Me.

9: The spaghetti's going out of the pot and into her bedroom.

I: Good anything else?

9: Im gonna make Tony.

I: What?

9: Him.

I: Oh Tony, Big Anthony.

9: I forget.

I: Anything else?

9: No.

I: Okay 7.

7: He has to eat up all the spaghetti and she's sleeping in her bed and I bet she feels very happy sleeping in her bed.

I: Good. Anything else?

7: No.

Group 3

Presentation 3

Bhueberries for Sal

Act.

Introduce story.

9: I heard that story from the library.

8: I read that.

Read story.

Introduce activity.

I: Now the people in the book were?

9: Little bear.

7: Big bear.

8: Little Sally.

9: And his mother.

I: Who do you want to be?

7: Little bear.

9: Big Bear.

8: Sally.

I: Who can I be?

8: The mother.

I: We have blueberry bushes where can we put them.

9: Over there.

I: Okay the only thing about over there is the camera can't see it.

7: How 'bout over there.

Set up bushes. 
8: Where can we put the blueberries?

7: All over.

Spread blueberries out.

I: I don't think the bears are at the beginning of the story.

7: We'll hide.

I: Where are we going?

8: I don't know.

7 \& 9: Blueberry picking on Blueberry Hill.

Drive car.

Putting blueberries in bucket. Kurplink.

I: What is Little Sal doing?

7 \& 9: Eating them.

8--needs direction.

7: Can the bears come out yet?

I: We're coming to that part ( 8 sits and eats berries)

7: Can the bears come out?

I: Now its time.

$7 \& 9$ act out their parts with some support. (8 needs more)

Use book.

8--needs to be told what to do.

I: Birds go Caw, caw, caw.

I: Follow the mother bear.

7 acts out following Sal's mother.

9 helps 8

7 acts out part eating in bucket with no prompting.

I: All go looking for their moms.

7: Now they go down this side.

I: And we drive home.

Children need quite a bit of story support.

They use actions not words to act the story out.

7 and 9 knew what was going on.

8 really needed to be directed as to what he should be doing.

Group 3 Presentation 4 Sylvester and the Magic Pebble Act

9: We get to act out the story again I think.

8: What story are we listening too.

7: He always wants to know.

I: Introduces story.

8: Let's see what we could be like we played with the blueberries.

I: Continue introduction.

Good attention.

I: Rock next to pebble.

9: There's the pebble.

8: I want to pick who we are. 
I: When we're done.

Continue story I: He felt he would be a rock forever.

9: Maybe he will be in the rock.

Continue story.

9: I bet the leaves aren't even cool.

Howls for the coyote.

Continue story.

9: And the pebbles still there.

The End.

Introduce Activity.

8: I want to be the lion.

I: Okay what else is there?

9:. I want to be Sylvester.

7: I want to be the piglets.

I: Okay, who can I be.

9: Sylvester's mom.

I: Okay we need someone to be Sylvester's dad.

T: 7 can you be the dad and the piglets?

7: Yes.

Get materials together.

All: The stones.

I: Let's use the book to start the story.

7: And there's the little red pebble in your hand.

I: That's right. Let's start the story.

7 takes the book and finds the first page.

7: This will be the little table. Now we just need one chair. The dad's sitting in the chair.

I: Oh I sit here.

9: You're the mother.

I: That's right.

9: And she's cleaning.

I: Should I be cleaning?

7: You don't have too. Pretend we have a house keeper instead.

I: Good idea.

9: And this can be my pebble collection.

7 turning page.

7: Okay 9 you're in the rain. Put some of the rocks on the floor.

7: Don't forget to find the red pebble.

I: What's it doing outside?

7 and 9: Raining.

7 directs 9.

9 picks up role making wishes to stop the rain.

8: Whose gonna go to the lion?

7: Here comes the lion come on out.

Crawls out. 
9: I wish I were a rock.

9 helps 8 do his part.

7 helps 8 do his part.

7 turning pages.

7: 9 You're still the rock and you're sleeping inside the rock.

7: Now I have to be the neighbor.

I: 8 You need to be the dad.

8 needs direction.

8: Have you seen Sylvester?

I--holds book.

Animals looking.

Mom and dad sad.

8: Who can I be?

I: You can come be sad with us.

7: Coyote.

I: And spring comes.

7: I'll be a little flower.

Get ready for picnic.

8: Who can I be?

I: You can be the dad.

7: Ill be the little piglet who comes with them.

Set up picnic on 9's back.

Investigator directs picnic.

Sylvester turns into himself.

All hug.

I: Sylvester can tell us about what happened.

Children still hugging.

7 and 9 less support.

8 Lots of support.

Group 4

Presentation 1

Blueberries for Sal

Art

Introduce story.

12: Oh goody.

11: Hey I heard this.

12: Oh goody.

Complete Introduction.

11: After we do all this what do we do?

I: We go back to your class.

I: eating berries.

11: Both of them are doing it.

Story. Sal Picking.

11: How can she reach the ones that are very high.

I: She probably just ate the low ones.

Part about bears. 
11: That's the mother.

I: Mother walking along.

11: I don't think so.

The End.

Introduce activity.

Children help set up tables and chairs.

Investigator explains how to glue on bushes and berries.

I: Glue the blueberries anywhere you like.

12: But not on top- of each other.

I: Look through the book and look at what you want to do.

11: Im doing the pail and Little Sally having it in her hand.

12: I want to draw this part.

I: With Little Sal eating blueberries.

10: This is Little Sally.

Children work gluing and coloring.

I: 10 who is this?

10: That's Little Sally.

I: What's she doing?

10: Dancing.

Children working quietly.

I: (to 12) You're drawing a bucket too.

12: That's a handle.

12: Im drawing Little Sally.

12: What color are her eyes.

I: You can color them any color you want.

I: 11 are you putting blueberries on the page?

11: Im making Sally drop some.

11: Im gonna save these two for ones Sally drops.

10: There's gonna be one up in the air cause Sally's throwing one up in the air.

Children still taking turns with glue, gluing blueberries.

I: Sal's throwing them

10: Yeah, this one its coming right down the side.

I: Neat.

10: I need to make grass.

12: I need to make her stockings.

11: I made her face purple.

I: That's okay.

10: Its snowing.

I: Its snowing in the story?

10: Yeah.

12: I need to make her shoes.

I: What else can we make in the story?

I: 10 has Little Sal and she's throwing blueberries up in the air.

10: If we want it to we can make it be Spring. 
11: Im doing snow but I don't have no white so Im using this color.

I: I don't remember snow in the story.

Children quietly work.

10: But it really did snow in the picture because of that (points)

I: Because of blueberries.

10: Because of that white stuff.

I: Oh I see why you think its snowing because the pictures are black and white. I think its just the way they make the pictures. I don't think its snow.

10: Its snow.

I: Okay. Although it doesn't usually snow when its time to pick blueberries because they don't grow. They grow in the Spring time.

10: Well its still starts snowing when the mom picks her blueberries and Sally.

I: Oh I see.

10: Well its snowing on her hand. Its snowing everywhere.

11: Im making it snow on her head.

I: What else can we draw about?

Children quiet.

11: Im making the ones near the people big ones and the ones in the sky small ones.

I: Good. Let's look through the book.

10: Blueberries everywhere.

10 takes the book to look through.

I: What else are you going to draw 12 ?

12: The sky.

10 hands teacher the book.

I: 12 why don't you look at the book.

12 takes book and thumbs through it.

I: 11 what else are you going to do?

11: Can I do some....I'm gonna do some birds.

12. I want to do this part.

I: What part?

12: Sally and the momma.

11: That's gonna be hard. You have to do the car too.

12: Do I have to do the car?

I: If you want to you can.

11: Don't do it 12.

12: I want to do the grass.

I: 12 can do what ever she wants its her picture.

11: Im making a duck

I: The ducks flying that's great.

10: Im making a tree. That's a tall tree. This is a tall tree.

I: Its a tall tree?

11: I did his tail and his wings.

12: I can't think of I can't make the mom holding the hand.

I: Oh she's too far away to hold her hand. That's okay. 
11: Im gonna draw a bird right here.

10: Im drawing a tall tree.

12: (to 10) That's a tall tree.

11: Goes off on a tangent about how long he's been at day care an all his teachers.

12: Im going to make a bird.

10: There's a lot of spot birds in my tree.

I: Neat you're all making birds and trees.

I: What else are you going to draw 10.

12: An orange beak.

10 doesn't answer.

1210 did that too many dots.

10: There's gonna be a little bit of white snow on the blueberry bush.

11: Im done with my tree anyway.

I: If you're done put your name on the back.

10: See and there's the blueberry.

10: There's a little bit of white snow on my blueberry bush. (glue)

I: Ill wipe the ghue off.

10: But if you want you can leave the glue on.

I: 10 are you going to draw anything else?

10: Yeah.

11: Im drawing a worm.

10: I'm drawing the mama jump way so high.

I: The mama jumping high.

11: The worm's climbing up the tree.

I: Let's think for a minute what else is in the story?

12: A bear.

I: Does anyone want to draw about the bears?

11: The bears hard.

I: The bear's too hard?

11: Because you can't do his tail.

I: Oh I see.

11: Well $\Gamma m$ done.

I: Could you tell about your picture? 10\&12 make sure you listen.

11: I drawed Sally holding her bucket getting some blueberries and I made some blueberries on the bush and I made some snow coming down from the sky and people are going and they can't get it from the sky. And birds are flying and I made a tree and the duck is trying to get the bird on the tree.

12: One worm?

11: What do I do next?

10: Im done.

I: Let's listen to 10 tell about her picture.

10: This is the blueberry bush and this is just the car and the other window broke off. And they didn't paint the car yet. This is a tree and its snowing and um Little Sal's mother jump so high and Little Sal. 
12: I'm all done.

I: Good why don't you tell us about yours.

12: Here's little Sally. Little Sally in the blueberry and her bucket in the tree. And a worm and grass.

11: Where's the worm?

12 points to it.

I: Anything else?

12: And a bush and a bird and a sky.

Group $4 \quad$ Presentation 2 Sylvester and the Magic Pebble Art

Introduce story.

I: Rain came shooting down.

11: Again 2 times.

I: Lion walked around him.

11: You know what? Good thing he didn't see his pebble.

I: Sylvester was a rock.

11: I think the donkey's inside.

I: Went to police.

11: Pigs were police.

I: Dogs looked.

11: They should picked up the pebble and wish it were Sylvester.

I: Did they know it was Sylvester?

11: No they thought it was just a red rock.

Continue reading.

Good attention except 12 who was playing with her hair and needed redirection a few times.

The End.

Introduce activity.

Children set up tables.

I: Remember we use the book to give us ideas about what we can do.

Pass out Paper.

I: One thing in the story that is on almost every single page.

11: The one that when he was a rock and then he turned into a donkey.

I: Is that what you are going to draw? Good. But what is on every page? (hold up pebble)

12: The red pebble.

I: Use the book to draw any picture you want.

11: I did a great job the other day.

12: Me too.

I: If you can't remember use the book.

10: Her shirt is inside out. The sleeves on her shirt is inside out.

I: 12 what are you going to draw?

10: Her sleeve is inside out on her shirt.

11: Im done with the magic pebble. 
10: Im gluing mine on.

12: $\mathrm{Im}$ decorating mine.

10: He throwed it up in the air.

11: That's what she did in the other one.

12: She threw the blueberries up in the air.

I: He's throwing it up in the air and who's this?

10: His mom.

Quiet working.

I: 12 what part are you drawing?

12: The part that she was sitting at the window crying.

11: Look it. There's my pebble.

I: What are you drawing?

11: Now Im gonna make the lion.

11: First, $I m$ gonna make the grass.

I: Would you like me to show you the pictures.

11: Yeah.

10: Its a rock.

I: 10 what part are you drawing?

10: Im drawing the part with the mom right over there.

I: Would you like to look through the book to find a part with the mom in it.

10: Yeah.

10: Ill draw the house next to it and the mom will be outside.

I: Here's a picture with the mom.

11: That's hard.

I: Well 10 can make her choice.

11: Is this how you make a lion.

I: It's a great lion.

10: Now Im going to paint their house.

10: Purple

I: 12 What part are you going to draw?

12: The rock.

10: They started painting.

I: 12 would you like to look through the book to see what page you want to draw.

12: Yeah, looks through it. This part.

I: Before he found the pebble.

12: I gotta draw a table with rocks.

I: 10's painting her house and her mother.

10: Well $\mathrm{Im}$ not done painting.

11: Im gonna make the grass.

I: Good lets look at the picture.

10: This is a pretty beautiful house.

I: It is.

12: Im gonna do the chair that he was sitting in.

10: This house is gonna be almost finished. 
11: I made a flower.

12: I know what I'm doing.

I: What?

12: Im doing the part what um the mother is watching him do the pebbles.

10: Im drawing a different house.

I: Good.

10: On this house there's purple, red, yellow.

12: A big sky.

12: This is just right.

Marker talk.

10: This is gonna be a pretty house after they paint is cause daddy's painting it.

I: Are they painting it in the story?

10: No just in my picture.

11: Im making a plum.

12: Pretend ghue got on this.

I: If you're unsure about what else to draw take a look at the book.

12: Okay. (takes the book)

11: I'm making pebbles.

12: Making my pebbles. Im making my pebbles.

10: There almost finished painting his house.

11: Im all done.

I: Name on the back then you can tell about your picture.

10: But they gotta build the roof.

I: Listen to 11 .

11: I made a lion and some grass and a flower and I made a rock and some pebbles and a lion in the grass and a daisy on the grass and I made the sky and I made the pebble.

I: Where's Sylvester?

11: I couldn't make him.

I: But where is he in the picture?

11: The rock. So he's the rock.

10: Im making a lion.

I: Are you ready to tell 10? Let's listen.

10: This is their house. This is the rock. That's the red pebble. No one touched it yet but his mommies gonna touch it but she didn't touch it yet but that's the house. That's the mom. But where's his sister at home?

I: Im not sure he has one.

10: Sylvester isn't a boys name its a girl name.

I: So Sylvester's a girl.

11: It looks like a boy to me cause he has short, short mane. That one is a little bit longer.

10: He's really a girl but he looks like that because he cut his hair.

I: Good, 12 are you ready?

12: I made the lion and the pebble and I made the table, the door. I made the sky. I made the rock and the door. 
11: 12 you forgot the mane.

11: She can make it like that cause girl lion's don't have manes.

Quite a bit of support needed

Group $4 \quad$ Presentation 3 Stone Soup Act

10: I saved your seat.

I: Thank you. Does introduction.

11: Oooh we haven't done this. (act)

Introduction.

11: Oh I heard this story.

I: 2 days.

11: 2 days whoa.

I: They're hiding all their food.

11: Why?

I: Because they didn't want the soldiers to get it.

Continue reading. ---dark.

11: Its night now.

The end

Redirecting needed a few times.

Introduce activity.

I: What are the characters.

11: when they were hungry.

11: The soldier.

I: The soldiers and peasants.

11: I want to be a soldier.

10: I want to be her.

12: I want to be a soldier.

I: Let's see what we need.

10: We need a bucket for a pot.

I: Good thinking. Bring blankets and pot.

I: And we need our soldier hats and a peasant woman hat.

I: Let's put all the things we need on the chair.

11: Put the pot on first.

12: Then the blankets.

Children put hats on.

Let's get started. Set the scene.

I: How does the story start?

Investigator has to direct. Starting scene going to village.

Hiding food.

A lot of support from book and teacher.

Everyone hides food. No true leader.

Investigator has a very active role. Had to tell the children what to say.

I: What do we need to do?

12: Food. 
I: Is that what you need to do? We're acting.

Go to houses. They hid food. No food.

Children start to catch on a little.

11: Starts to pick up on acting.

10: We can find our food.

10-- has a general idea of acting skips ahead a lot.

12: Concerned about soldier hat.

10--takes over as soldier, puts rocks in.

Investigator directed.

Making soup. Soldier's making. 10 getting food.

12 cutting food.

11 stirring food.

Name vegetables, salt, pepper, carrots, cabbage.

10: And they said for potatoes.

I: Soldier ask. Where's the milk

Children start to do roles.

Investigator narrates and directs children to look at the pictures to get them to plan.

Set up tables.

10 takes over.

12: Tll help set up.

Sit down to eat soup. 11: dishes it out. Children pretend to eat.

10: We're eating broccoli.

Clean up.

Dancing at out party.

Its getting dark.

Soldiers getting tired. They go to bed.

Name beds--

10 as villager is concerned about her bed.

11: Priests house.

12: In the I forgot.

I: Baker's house.

Third soldier in mayor's house.

Pretend sleeping.

10: I have to wash my face and brush my teeth before I go to bed. Pretends to brush.

I: Its morning.

10: I haven't gone to sleep yet.

Time to get up and say good-by.

Villagers thank soldiers and soldiers leave.

Clean up.

A lot of support needed.

Group 4

Presentation 4

Strega Nona

Act

Introduce story.

11: I like the one we did. Stone soup. 
I: Start story.

I: She had a magic touch.

11: What's a magic touch?

12 moving around a lot.

11: Why Big Anthony don't want him to touch it.

I: Strega Nona doesn't want him to touch it. Its valuable.

11: What's valuable.

I: Worth a lot of money and very important.

11: Oh.

I: Pasta all over.

11: You know what they could make a trap for it.

I: Good idea.

The end

11: She tricked him because she was in bed.

Introduce activity.

I: Who wants to be who?

11: I want to be when that was the one that had the pasta.

I: Big Anthony.

11: Yeah.

10: I want to be the lady.

I: What lady?

10: The lady who has the pasta pot.

I: Strega Nona.

I: 12 do you want to be the townspeople with me?

Investigator directs scene.

Tells 12 what to do.

Tells 10 what to do.

Lots of direction.

Strega Nona helping townspeople.

Put up a sign.

Investigator uses the book and narrates, telling children what to do. Pauses and leading questions don't help. The children just stand there.

$10 \& 11$ pick up a little bit of acting.

Strega Nona hires Big Anthony.

Big Anthony working. Strega Nona making pasta.

Start and stop. Big Anthony watching. Strega Nona blows kisses.

Follow story line.

12 joins for dinner. A friend coming over. Children set table, sit and eat.

12 doesn't stick to role well at all. Calls Strega Nona by her real name.

11: Big Anthony cleans up--washes dishes and puts them away.

10--switches to other peoples roles.

Big Anthony tells town.

11--acts with some direction.

12 needs lots of directions. 
10 --needs directions.

11 helps 10.

Strega Nona leaves.

Big Anthony makes past. Calls town. Serves pasta.

Town eats.

Bows to crowd.

Pasta keeps coming out. String coming out of the pot all over the place.

Sits on pasta pot.

Mayor tells everyone to get things to make a barricade.

Strega Nona comes home. Sings song, blows kisses and stops the pasta.

Strega Nona tells Big Anthony to eat all the pasta.

10: Needs directions on what to say.

Big Anthony eats pasta.

Strega Nona goes to bed. 


\section{APPENDDX E}

Child 1 Presentation: 1 Story: Stone Soup Activity: Acting Group 1

C: We did./ We were making the soup and with the milk./

And we put so many vegetables in: potatoes and carrots./

So carrots and potatoes make 'em better./

And then they./ And the other guy say, "Thank you for making us, showing us to make that soup/ and then they went off./

$\mathrm{T}$ : Is there anything else that happened in that story?

C: One day the first one.../ Where does he sleep?/

T: Its okay if you don't remember.

C: The first one, he did,/ I don't remember./

T: Okay, where did the second on sleep?

C: The second one he sleep in the village. / And the last one slepted in a ... where all the village so they slept./

T: So they slept. Is there anything else about the story?

C: No/

Child 1 Presentation: 2 Story: Strega Nona Activity: Acting Group 1

C: Ill show you a book./

T: No, you need to tell me the story.

C: The little girl where Strega Nona is./ Don't touch this hot pot cause you'll get not Strega.../ She does three kisses (Child makes kissing noises) in it. / Then all the town passes../ Then all the town passes it.

T: Okay, She blew three kisses and then all the town people what?

C: Strega Nona soup was getting...tried the magic word but it didn't work/ and a there's so many persons and a they a./

T: Strega Nona tried the magic words and they didn't work so what happened?

C: Strega Nona tried the magic word/ and then one day they said "The soup is getting stronger it blowed Strega Nona up"./ And then the mom and the cows were ....the cows were /

T: They took her to the cows and the moms?

C: The cows and the moms, they said "Well one day this is not a good day Strega Nona, this is not a good day./ Cause. Don't touch that hot pot."/ Then everyone left./ Then one day.....

T: Okay, and then one day what?

C: They were singing a song./ He tried the magic word two time. / "Strega Nona, Strega Nona"./ Then one day Strega Nona she had to eat all that she made and then the mama nighty nighty./ And the. And then one day.../ and I don't know the rest./

T: You don't know the rest of the story?

C: No./ 
Child 1 Presentation: 3 Story: Bhueberries for Sal Activity: Art Group 1

C: Yes, Uh... When I was a girl, I eated... / Um a... In the book?/ In it?/ Sal's mom didn't get mixed up./ Cause I been doing the right one./

T: Cause you've been doing the right one? Okay, Could you sit down on your bottom and move close. And I need you the tell me the story you heard.

C: The story?/

T: The story you read, the book. Could you tell it to me?

C: Um Well Sally, Sal's mom go picking berries/ and she was gonna eat all of them/ and she took a handful of mommies./ And ....

T: Okay, she took a handful and then what?

C: She ate them all./

T: And then what happened?

$\mathrm{C}$ : And then one day they went home/ and they made some blueberry crunch outa a blueberry cause they put them together./ But we didn't know what which so they mixed 'em up and put 'em in the jar./

T: So they mixed it up and put it in the jar. Okay, what else happened in the story?

C: I forgot that part./

T: Could you tell me what happened to Little Sal in that story?

C: Yes, I don't know what you said./

T: Sit down and tell me what happened in the story.

C: Sal and her mom went blueberry picking./

$\mathrm{T}$ : They went blueberry picking. Then what happened?

C: Then what happened...They... / One day they were saying...ow.. and don't do that.... and don't pick my blueberries./

T: And after that what happened?

C: I forgot that part./

T: Is there anything else?

C: No

Child 1 Presentation: 4 Story: Sylvester and the Magic Pebble Activity: Art Group 1 C: Yes, Uh One.. the sun was rising up./ The sun was rising like that and then he was.. "Im tired I better go back to sleep."/ Then it was still morning, he was tired./ Then it got to be night time/ then the sun rose up./

T: Could you tell me about the story Sylvester?

C: Sylvester?/

T: The story Sylvester that we just listened to?

C: Sylvester, Sylvester./ The rock went to the... the rock.... the little rock thing went into a rock./

$\mathrm{T}$ : It turned into a rock?

C: Yes, and then nothing happened./ Tried to turn/ and he didn't turn back into a kangaroo./

T: He didn't turn back into a kangaroo. Then what happened.

C: I don't know that part./ 
T: Okay, then what happened after that part.

C: Then one day Sylvester..... I

T: Sylvester what?

C: He was tumed in a.../ He couldn't wake up/ and he can't breath./

T: He couldn't wake up or breath? And then what happened?

C: One day he turned back to a rock/ and he still couldn't breath./

T: He still couldn't breath.... Then what happened?

C: I don't know this part.I

T: Okay, what happened after that part?

C: Uhhh, Sylvester....../

T: Sylvester what?

C: He was ......

T: Sylvester was what?

C: He said "I can't breath. I can't breath."/

T: Okay Sylvester said I can't breath, then what happened?

C: I don't know the rest./

T: You don't know the rest. Do you know anything about how the story ended?

C: He turned back to a kangaroo./ And I don't know the rest./

T: Okay, Come sit.

Child 2 Presentation: 1 Story: Stone Soup Activity: Acting Group 1

C: There was .../ There were soldiers that were hungry./ And the people that lived in the village, they pretend that they didn't have any food./ The soldiers said..../ We will make stone soup/ and then they got everything for it./ And then they and then after they ate and dranked/ and then they danced./ And then they were sleepy /and they slept./

T: And then what happened.

C: And then it was morning/ and they went away./

T: Anything else?

C: $\mathrm{No} /$

Child 2 Presentation: 2 Story: Strega Nona Activity: Acting Group 1 C: The pasta went out of the pot/ and they tried to block it./ But it wasn't any use cause it kept going and going./ And then she came back/ and she said "eat of all the pasta"./ T: Okay, did anything else happen in that story?

C: No/

T: Could you tell me what happened to Big Anthony?

C: He ate all the pasta./

T: And what did Strega Nona do?

C: Blew three kisses and said stop./

Child 2 Presentation: 3 Story: Blueberries Activity: Art Group 1 C: Well they each got mixed up because the bear was with Sal's Mom and Sal was with the Bear's Mom./

T: Why don't you tell the story to me? 
C: They were going to can blueberries for the winter/ and the bears were getting food for when they were hibernating./

T: Good and then what happened?

C: They went home./

$\mathrm{T}$ : Did anything else happen?

C: They were shy./

T: They were shy and then what happened.

C: And they went to look for their kids./

T: Okay and then what happened?

C: And then went in the car/ and then they went to hibernate./

T: Anything else?

C: No/

Child 2 Presentation: 4 Story: Sylvester Activity: Art Group 1 C: Um He was counting on his pebbles/ and he found a magic pebble/ and it wasn't raining out/ and he asked it to stop and it did/ and then he asked it to go again/ and then he asked it to stop/ and then he saw a lion/ and then he asked the pebble to turn him into a rock/ and then um he.... And then there was a wolf howling on him/ and they were worried/ and they asked the neighbors/ and they went to the police/ and they didn't saw him. And then they went on a picnic/ and then the dad saw the pebble/ and then the mommy was her/ and then she said, "I wish he was back"/ and then he turned into himself again./

T: Anything else?

C: No/

Child 3 Presentation: $1 \quad$ Story: Stone Soup Activity: Acting Group 1 C: Once upon a time there was three soldiers./ One soldier said "I see a village and I'm very hungry. Maybe they can help us."./ So they went to the village./ And the village saw the soldiers so they hide the food./ Pieces of roast beef, milk, carrots, potatoes and salt and pepper. /

$\mathrm{T}$ : Okay, and then what happened?

C: Then the soldiers asked for food./ And they said, The villagers said, "We are starving. We have no food again."/

T: They had no food again, then what happened?

C: The villagers./ The soldiers talk to each other/ and then they said to the villagers, "Let's make stone soup."/ And the villagers said, "What is stone soup?"./ And then they said "if we light a fire and we had a big bowl and add some stone"./ People got big stones and put them in/ and then they made stone soup./

T: Good and then what happened?

C: Then one sleeped in the mayors and the bakers house and I don't know./

T: That's okay and then what happened?

C: They got up early/ and then they said "thank you for helping us make stone soup."/ And they lived happily ever after./

$\mathrm{T}$ : Anything else you want to add?

C: No./ 
Child 3 Presentation 2

C: Once upon a time, there was a lady Strega Nona./ She fixes warts and fixes headaches./ One day she was getting old./ She put up a sign calling "Could you please help me"./ And then the man carried the sign to Strega Nona/ and she said, "Rake the leaves and then pick the vegetables and don't touch the magic pot."/

T: Good, okay.

C: And then he went to the village/ and he told them about the magic pot/ and they said, "Couldn't be."/ And then Strega Nona went away/ and He said "I know a trick to the magic pot."/ And he went and got the pot/ and he said the magic words./ And it flowed over the top and wrapped.../

T: It flowed over the top and wrapped the?

C: The town./

T: The town, okay and then what happened?

C: Strega Nona came back/ and she said um/ she did the three magic kisses and it went away./

T: It went away and then what happened?

C: He ate all of it up/ and that's the end of the story./

Child 3 Presentation: 3 Story: Blueberries Activity: Art Group 1

C: Once upon a time... Sal and her kid went blueberring./

T: Sal and her kid went blueberring and then what happened?

C: They picked blueberries./ She got three blueberries/ and they went plunk, plunk./

T: Good and then what happened?

C: She ate the blueberries/ and then she picked and ate more./ And then and then./

T: Okay she ate the berries and then what happened?

C: She went near her mom/ and then by mistake she dropped a blueberry in her moms bucket./ She was going to take out her blueberry and by accident she took out a whole bunch of them cause they were all close to each other./

T: They were all close to each other and she picked a whole bunch and then what happened?

C: Then the mother turned around and said go and pick your own berries./ And they got and and./ And a bear came and and said "Eat all you can so you can get fat."/ And then they got switched./ And then the mother heard someone tripping along and thought it was Sal and turned around but it was ....

$\mathrm{T}$ : The mother thought it was Sal tripping along and then what?

C: and then they and they, they./

T: The mother thought Sal was tripping along and then what happened?

C: She turned around and saw a bear.../

T: She turned around and saw a bear and then what happened? You're doing great.

C: They Then Sal got switched with the mother bear./

T: Okay Sal got switched with the mother bear and then what happened?

C: And they turned around and said "get my son." /

T: Good and then what happened?

C: And then Sal's mother is looking for Sal/ and the bears are looking too./ 
T: Good and then what happened?

C: And then the bears went home/ and they both went home./

T: They both went home and then what happened?

C: And then they were going to make blueberries in the jars./

\section{Child 3 Presentation: 4 Story: Sylvester Activity: Art Group 1}

C: Once upon a time../ He was looking at his own collection of pebbles/ and he went out looking/ and he found a magic pebble/ and he went./ And he wished it would stop raining and it did./

$\mathrm{T}$ : He wished it would stop raining and it did and then what happened?

C: He went walking home/ and he saw a mean old lion/ and he wished he turned into a rock/ and he did./ And his mother and father got worried/ and they asked everybody in the town if they saw him/ and they said "No"./ The dogs went looking for him/ and they couldn't find him./ They went on a picnic/ and he turned back into a donkey./

$\mathrm{T}$ : And then what happened?

C: They went back home./

\section{Child 4 Presentation: 1 Story: Blueberries Activity: Acting Group 2}

C: Okay, Sal and his mother went to get blueberries/ and the mother kept thinking and thinking about picking the berries for the weekend./ Then came the big bear/ and they were eating blueberries/ and then they got all mixed up/ and she said, "What you're not my son."/ And then they got back to their right mothers and fathers./

$\mathrm{T}$ : Good anything else?

C: And they went back home and put the cans in the blueberries./ I said "put the cans in the blueberries."/

T: I know what you meant. Did anything else happen?

C: And that's the end of the story./

\section{Child 4 Presentation 2 Story: Sylvester Activity: Acting Group 2}

C: Okay, Sylvester was collecting his pebbles/ and then he went looking for pebbles./ It was raining, pouring on his head./ He wished it would stop raining and it did/. And then he, when he was going home a lion camed so he wished he was a rock./ And then his parents were so worried/and then they went for a picnic on Cherry Hill/ and then they putted the pebble on Sylvester/ and then they um then Sylvester wished he was himself again and he was./

T: Okay and then what happened next?

C: They went home and they went home and didn't use the pebble./

T: Is there anything else?

C: No.l

Child 4 Presentation: 3 Story: Stone Soup Activity: Art Group 2 C: The soldiers were walking down the road/ and they came to a village/ and they wanted to get some food./ So when the villagers saw that the soldiers were coming they hided all their food./ The soldiers went around walking and talking, asking people if they have 
some food or lay in a bed./ And they soldiers said, "Well you have no food. What we'll have to do is make stone soup." / So they got all sorts of things like carrots, stones, some fire, and so then they all had a great party./

T: They all had a great party, Okay.

C: And then what happened was um they had a great party/ and they got to have beds./ They went right to sleep./

T: They went to bed and tried to sleep, Okay.

C: And that's the end./ And they walked down the road./

And they walked down the yellow brick road.I

T: I think you're adding things in. Is there anything else you would like to add?

C: No./

Child 4 Presentation: 4 Story: Strega Nona Activity: Art Group 2 C: Well, Strega Nona was a witch so they wanted to they came to fix things even the priest./ So one day she was getting older./ So what was his name? /

T: Big Anthony.

C: Big Anthony came/ and he had to do all the work for Strega Nona./ So then....

T: Big Anthony's doing all the work, then what.

C: So he told them. Strega Nona was making spaghetti so then what happened was they Anthony, Big Anthony told all the people that/ and the people didn't believe him not even the priest./ So um. Strega Nona went out to see her sister/ and he said, "Ah ha, now its my chance."/ He thought to himself./ Then...

T: Now is his chance, then what happened?

C: He made the people spaghetti but the spaghetti kept on coming out./ So he forgot the three kisses./

T: Okay then what happened? C: I forget?/

T: The spaghetti's over flowing and he forgot to do the three kisses.

C: And then she comes back/ and she does the three kisses/ and he has to eat all the spaghetti//

T: Anything else. C: No./

Child 5 Presentation 1 Story: Blueberries for Sal Activity: Acting Group 2 C: First, they went up,/ Sal and the mother went up blueberry hill./ The mother and Sal started picking blueberries/ and then Sal ate, picked and ate the blueberries./ And on the other side um bear and his mother were coming up the other side and eating the blueberries./ And then um um Sal ate some of the blueberries in his mother's pan./ And then his mother said, "Sal you must go play"./ So she did/ and then she she got mixed up with the bears/ and little bear got mixed was with Sal's mother/ and Sal was with Little Bear's mother./ And then um um Little Bear's Mother saw Sal./ She said, "Where is Little Bear?"./ And Sal was looking for her .../ And Sal's mother saw um saw Little Bear./ And then and then Sal finds her mother/ and Little Bear finds her, his mother./ And then Little Bear and her mother went home/ and Sal and her mother went home too./ And then when Sal and her mother got home they canned the blueberries./

T: Great job. That was a great story. Do you have anything else? C: No./ 
Child 5 Presentation 2 Story: Sylvester Activity: Acting Group 2 C: First, um First, um Sylvester was counting his pebbles/ and then the mother was cleaning/ and the dad was reading the newspaper and smoking his pipe./ And then Sylvester was studying the magic pebble, the magic pebble./ And then said, "I wanted it to rain again. I wanted it to stop raining." So and it stopped raining./ And then he walked home./ He got but he met the lion, the lion that was mean./ Sylvester said, "I want to be a rock." ./ And the magic pebble turned him into a rock./ And then he wanted to be back to himself again but he couldn't because he didn't have the pebble on him/ And Mrs. Donkey and Mr. Donkey were sad and asked everyone for him, everyone if they saw Sylvester but they didn't not even the police/ so everyone searched and kept doing it and doing it for a whole month/ and then they went out for picnic./ And then Sylvester got turned into himself again./ And they hugged and kissed and hugged and kissed./ And then the end./

T: Anything Else?

C: No.l

Child 5Presentation: 3 Story: Stone Soup Activity: Art Group 2

C: First, there were three soldiers walking down the lane after the war./ They haven't had anything to eat in two days so they were starving./ And then they saw a village/ and then the people hided their food./ And the soldiers went there and asked every people if they had anything but they didn't./ Because they hided it./ And then so they said so the soldiers said, "Let's make stone soup."/ So the so they said, "We need a big pot"/ and people went to get the biggest one they could find./ And then they got wood to start a fire./ And then got carrots and beef and lettuce and cabbages and carrots to make stone soup./ And then there was a party/ and they served stone soup/ and they had cider and bread, butter/ and then they they the three soldiers went to their place/ and so the people were happy/ and they say to the soldiers, "We'll never go hungry because we know the recipe for stone soup."/

T: Good, anything else?

C: That's it./

Child 5 Presentation: 4 Story: Strega Nona Activity: Art Group 2

C: First, there was this a small village./ And there was a women called Strega Ona/ and everyone came to see her for all sorts of things even the priest./ And then she but one day she was getting too old/ and she needed someone to keep her... to to sweep her house/ and she got and to do the work in the garden, feed the goats and cleanup the goats and she she um Big./ What's his name?/ T: Anthony Big Anthony can um Big Anthony did all the work./ And then one day, Big Anthony heard um a lot of singing/ and um he peeked/ and it was um a pot/ and she said that she wanted to have her dinner/ and it cooked pasta for her all by itself./ And then um and then Big Anthony he wanted to do it./ So one day Strega Ona had to go somewhere over the mountain/ and then he got he had his chance./ So he so when Strega Ona was gone he he made the pasta cook/ and the everyone said get forks and plates and someone did/ and then he said the and then everyone went to Strega Ona's house/ and everyone wanted some/ and he said stop,/ he said the magic words to make it stop but it wouldn't because he didn't see the three.../ 
Cause she cause Strega Ona blew the three kisses, / he didn't see so he didn't know to do the kisses./ And then and then it was crowding the house it leaked/ and it kept going and going into the street and into the town/ and then Strega Ona came back/ and she said the magic words and blew the and blew kisses the three kisses./ And then and then she um then she and then its dark/ and she and then and then he had he ate all the spaghetti/ and he got so fat./ And then and then he he didn't have a bed any more/ and Strega Ona slept in her bed./ The end.

T: Good job.

Child 6 Presentation: 1 Story: Blueberries for Sal Activity: Acting Group 2 C: Um, the Sal was the the the the baby bear's mother./ It was Little Bear's Mother/ and little bear um was with Sal's mother./ And she got she got um she got she got scared./ And she turned around/ and she said "that's not my my Sal, how come you're here."/ Then she, she, she, she um she was looking for um um her daughter./

T: So what else happened?

C: Um then they went to their house and packed the blueberries into jars./

$\mathrm{T}$ : Is there anything else that happened in the story?

C: Yeah./

T: Could you tell me about that?

C: Okay, Then after they went home and put the blueberries in the pots the mother told her to eat some./

T: Anything else?

C: No./

Child 6 Presentation: 2 Story: Sylvester Activity: Acting Group 2

C: Um Sylvester finds um a magic pretty rock/ and he wishes it to make the rain stop/ and he looked at it/ and then he saw a lion/ and he said, "I want a lion to.... I wish I was a rock."/ And then the lion looked around it and couldn't find him./

T: That's good. Go ahead.

C: Um then he was going crazy and he thought he needed glasses./

T: That's right.

C: And Sylvester sadly said nothing./ but he the pebble was far away so he couldn't reach it./ He couldn't reach it so he couldn't tum back to a donkey./ But went on a .... It was fall and it keeped fall/ and then um snow came/ and but a wolf went on top of him um um howled oww, oww, oww./ And and then it was spring/ and his mother and father went on a picnic/ and they was sleeping on his son but they didn't know that he was turned into a rock./ And the pebble was right next to him when they first find it/ and they and then they put it on the rock./ And his father is on the rock/ and the pebble and um he said, "My um son um he likes those, he likes collecting those rocks"./ And um it was the magic pebble they put on him/ and um and um he didn't know that/ and he said, "I wish um I wish I was back to help um us get much more happier."/ And um and then his wish came true/ and um he turned back into a donkey./
T: Good, anything else?
C: No./ 
Child 6 Presentation: 3 Story: Stone Soup Activity: Acting Group 2

C: Um the soldiers they were done with the war/ and they were so hungry/ and then they asked for ... to everyone./ They um they wanted um they talked to people asking if they had food./ And um they didn't have any but they forgot they had everything hidden./ Then then so the then and they and the soldiers asked all the um asked all the people/ then the soldiers said, "Lets make stone soup"./ And then the so the some soup... and they got some stones for it/ then they um got um some potatoes and um carrots and um uh salt and pepper/ and um I forgot what else./

T: So they put all the things in the soup and then what happened?

C: And then they after they were done they had um a big um feast and a lot of people/ and they sat at the table/ and then they they tasted the soup/ and it was good to them/ and then um and then they knowed how to make stone soup./ And then they the soldiers went away./

$\mathrm{T}$ : Okay, anything else?

C: No./

Child 6 Presentation: 4 Story: Strega Nona Activity: Art Group 2

C: Um Strega Nona um she helped everyone even when they had sores and sores with cuts/. And um then one day one day she um she saw she Strega Nona saw.../ What's that guys name? /

T: Big Anthony.

C: Big Anthony he he he um um helped do the work./ He cleaned and um um he did the garden./ That's all I can think of/ And then one day when Strega Nona um saw um took out the magic pot/ um um she said all the wishing words saying stop and go./ And um Big Anthony was peeking/ and she when she was when she went out for him/ Big Anthony wanted to tell everybody about the pot./ And they didn't believe him so they laughed./ And um um so they didn't believe him so/ and he didn't forget the magic words and the last magic words/ and he forgot the kisses because he was going he gave it to everybody, / he yelled out, " Go an go get your um go get some plates and forks and plates"./ And um they um ate some spaghetti/ and said just one thing but not the three kisses./

T: Okay, then what happened?

C: Um it growed and it growed and it growed and it went down the road/ and the king of the island said um "Get mattresses, get doors, get chairs and..." / um I forgot what else./

T: Okay, that's okay, what happened after that? Getting the things?

C: Well it growed and growed but they they but when Strega Nona um looked out of her friends window uh door she went back to her house/ and she uh gave three kisses./

T: Okay, then what happened?

C: That's all I can think of./

T: Anything else?

C: No./ 
Child 7 Presentation: 1 Story: Stone Soup Activity: Art Group 3

C: Um um the first hungry sold. The hungry soldiers and./ The first hungry soldier said, "Um I need something to eat"./ And the next hungry soldier said, "Im um We need a bed to sleep in"./ And the third hungry soldier said, "Don't bother"./

T: Okay, and then what happened?

C: And then they came to the village/ and they all had nothing to eat./ They said "We don't have nothing to eat for you and all beds are full."./ So the hungry soldiers had to make stone soup./ And the three hungry soldiers needed a pot of boiling water and/

T: What else did they need?

C: And um and she and they./ T: You're doing great. And um they asked for a pot some water and three smooth stones./ And then he asked for some vegetables; carrots, salt and pepper, carrots and let... cabbages and potatoes and some beef/ And then they had a big feast and dancing/ and they had ...the uh dancing and the and then they had some./

T: The dancing and the feast...

C: And then they had sleeping./ One slept in the church, one slept in the baker's and one slept in the mayor's./

T: Wow and then what happened?

C: And then they all went bye-bye./

T: Good job.

\section{Child 7 Presentation: 2 Story: Strega Nona Activity: Art Group 3}

C: Yes, Well she can fix headaches with oil and water and a hair clip/ and she can help pretty princesses find someone to marry./ Um T: Okay, and then what happened?

C: She could fix she could fix things./ And one day she put up a sign that she needed help./ And then Big Anthony came to visit her./ And then she said to Big Anthony, "You you pull out the vegetables, milk the goat and ..."/ and she came and she came and then while he was working outside Strega Nona was singing in the kitchen./

T: Good, and then what happened after Strega Nona was singing?

C: And then he walked to the window and looked inside/ and she went ...../

T: You don't have to remember all the words but she sang the song.

C: And she blew three kisses, 1,2,3./ And then he did...../

T: She blew three kisses and then what?

$\mathrm{C}$ : And then she said.../ Big Anthony was going out to the town to get water/ and he told every town every townperson, all the townspeople what they were doing, what Strega Nona was doing with the spaghetti and uh/ and all ganged on Strega Nona.

T: And he told the townspeople and then what happened?

C: And then Strega Nona told him she was going out to see her friend her friend./ She told him to pull the vegetables, milk the goat and feed it./ And then he thought he would have his only chance to do the spaghetti pot./ And then he he sang the magic words/ and he didn't give the three kisses./ He didn't see her do that so he didn't give them./

T: Then what happened? He forgot the three kisses.

C: And then he called the townspeople bring your platters, forks, bowls, dishes because I have very good spaghetti./

$\mathrm{T}$ : Good and then what happened? 
C: And then they and then they had a plate full of spaghetti and started and it started making..../

$\mathrm{T}$ : They ate plates full of spaghetti and then what happened? C: It happened when they um when they when um and they./ Well he forgot/ and then um the spaghetti went all over the town's streets./ And then who would come? Strega Nona./ And then she sang the magic words again./ And then and then she blew the three kisses/ and then the spaghetti went back into the pot./ And poor little Anthony had to eat it up./

T: He had to eat up all the spaghetti right.
C: And she finally got to sleep in her bed./
$\mathrm{T}$ : Good is there anything else.
C: No./

Child 7 Presentation: 3 Story: Blueberries for Sal Activity: Acting Group 3 C: Its a story about a little boy named Little Sal and his mom. And then they then he um and the he./ Um they are going to go out to pick blueberries for the next winter./ And they went to Blueberry Hill and picked lots of blueberries./ But not Little Sal./ He kept kurplink, kurplunk and (eating motion)./ T: And eating the berries.

C: And...

T: And Little Sal's eating the berries and then what happened?

C: Then they went down Blueberry Hill/ and then ... He sat down near a bunch of blueberry bushes and ate all the blueberries./ And then ... And then he did./ And then he and then he heard a rustling/ and he thought it was his mom./ The rustling noise... that wasn't his mom./

T: That wasn't his mom. Could you tell me about it?

C: And then Baby Bear sat down and did the same thing/ and he heard a rustling noise/ and he started looking for his mom/ But they both found birds. "Caw, caw, caw." and also "Flutter, flutter, flutter."/

T: Okay, so they both found birds.

$\mathrm{C}$ : And then he and then they went to go find there moms and then baby bear heard another rustling./ Well um not baby bear but Little Sal./ Little Sal heard a rustling noise then it was the bushes/ and then he found the bear./

T: Little Sal found the Bear.

C: He went this way and the other bear went this way./ Sal was just going along to blueberries./ And then the bear mom said "Come on we have to fill ourselves up with fat for the winter."./ But Little Sal picked three blueberries and went kurplink, kurplunk./

T: Okay and then what happened?

C: Then the mother bear turned around and said "You're not ba You're not my baby"./ And then the mother the mother of Little Sal heard "Crunch, Crunch, Crunch"./ It was the baby bear taking two big bites./

C: And then and then and then they./

T: Baby bear was just taking two big bites and then what happened?

C: And then she turned around and said "You're not Little Sal"/ And they both went off looking for their mothers./

T: They both wandered off looking for their mothers. Is that what your hands are doing?

C: Then Sal is there with his mom and little bear is there with his mom./

T: So you're using your hands to show me where everyone is? That's good. Okay and then. 
C: The Little bears went down this side/ and the mom and the little girl, and the mom the little boy went down this side./

T: Okay, anything else? C: No.

Child 7 Presentation: 4 Story: Sylvester Activity: Acting Group 3

C: Yes, Well one raining day... He walked to the park/ and then and then he holded the magic pebble in his hand/ and "Oh I wish it would stop raining"./ And then it stopped./

T: Okay and then what happened.

C: And then he and then he wished it would rain again/ and he wished it would stop./ And then he wished he were a rock./

T: And then what happened?

C: He wished that for a long time/ and he was in it for a long time too./

T: Okay he was in the rock for a long time and then what happened?

C: And then he and then soon they went out on a picnic right./ And then his father was sitting./ And then he looked/ and he found the little pebble/ and he put the little pebble on the table/ and then he wished that Sylvester was there again so that he could collect rocks/ and Sylvester wasn't a rock anymore./ And Sylvester and they went home/ and they cleaned up and went home./

T: Good Anything else?

C: No.I

Child 8 Presentation: 1 Story: Stone Soup Activity: Art Group 3

C: Well um I made,/ Well I liked the soldiers/ and I made it/ and when I made it I liked the soldiers when I maded it because so I can make it./ Because I wanted to make it so I can learn what picture I am on/ and I want to make a picture./

T: You remember the story Right? Could you tell me about that story with the soldiers and townspeople and what happened to them?

C: Well um well the soldiers saw that the and then they went off/ and they wanted better food./ And they went to the townpeople/ and they said "No their not"./ And and And then they. and.I

T: They went to the townspeople and the townspeople said no. Then what happened?

C: Then .... I don't know./

T: What else do you remember? After they went to the town what happened?

C: Um they wanted some food./ And then they hide some./ And then they wanted stone soup./ And then they put three stones in there/ and um then the eat/ and then they were dancing around/ and then they were tired/ and then they slepted./

T: Good. Anything else?

C: No.l

Child 8 Presentation: 2 Story: Strega Nona Activity: Art Group 3

C: Well I made Strega Nona/ and then I made... What else I made?/

T: Could you tell me about the story you heard.

C: I made Strega Nona and what else?/ I made somebody sleeping./

T: Do you remember the book?

C: Yes./

T: Could you tell me what happened in that book? 
C: Well spaghetti went all over the place/ and um and um It was boiling/ and it was bubbling/ and then I can't think what else./

T: Okay spaghetti went all over the place and then what happened?

C: I can't think what else./

T: Okay let's think for a second. Spaghetti went all over the place and then what happened next?

C: Mmmmm./

T: What was that?

C: I can't say it./

T: Well maybe I can help you. What are you trying to say?

C: Im trying to say the lady who was sleeping./

T: The lady who was sleeping her name? C: Yes./ T: Strega Nona

C: Strega Nona was sleeping/ and when the other guy go she went to bed./ She went to bed and she was grumbly./ And um she was grumbly because she went to bed./

T: Is there anything else you would like to tell me about the story? C: No./

T: Do you think you could tell me what happened to Big Anthony?

C: Well he was but he didn't blow three kiss./

T: He didn't blow three kisses and then what else happened.

C: He was... I can't think what else./

T: What did Strega Nona do?

C: Well she well she blowed three kisses/ and she started to sing/ and I can't think what else./

T: Okay, How did the story end?

C: Cause she went to sleep./

T: Is there anything else you want to tell me about the story? C: No./

Child 8 Presentation: 3 Story: Blueberries for Sal Activity: Acting Group 3 C: Well um they went in the car/ and then they drive/ and then they went to the blueberry hill./ And I can't remember./

T: Okay, they went in the car and they went to the blue berry field and then what happened?

C: And then the bears and then little Sally was looking for his mother and he./ And then the bear came to eat Sally's um Sally's um what Sally's mother was picking blue berries/ and the bear ate 'em./

T: The bears ate the blueberries. And then what happened?

C: Um I can't remember./

T: Okay the bear ate the blue berries and then what was happening?

C: And then they went all over looking for their mommies/ and then the just found 'em./ And then the bears went the other way./ And the mommy and the the../ What is his name?/

T: Little Sal.

C: Sally went the other way with his mommy./

T: Good, Anything else? C: No./ 
Child 8 Presentation: 4 Story: Sylvester Activity: Acting Group 3

C: Well they had a well he found a pebble/ and um he was./ I can't remember.

T: Okay, Ill help you. He found the pebble and then what happened?

C: And then he and then they started to cry because they couldn't find him./

T: Oh they started to cry because they couldn't find them and then what happened?

C: And they asked the pig they asked the police./ And then so and then he was a rock./ And then they and they they lived happily ever after/ and then they lived happily ever after./ And when they did they thought he was a rock./

$\mathrm{T}$ : They thought he was a rock and then what happened?

C: And then they went back home/ and then they started to rain/ and then they were going out to look for him/ and then they were having picnic/ and then they were uh/ and then they were./

T: They were having a picnic then...

C: And they saw he was a rock./ Then um um um./ I can't remember./

T: You're doing great. They saw he was a rock..

$\mathrm{C}$ : And then and then they saw the magic pebble./

$\mathrm{T}$ : Then they saw the magic pebble and then what happened?

C: And then they lived happily ever after./

T: And then they lived happily ever after. Anything else?

Child 9 Presentation: 1 Story: Stone Soup Activity: Art Group 3 C: They were walking/ and they found a village/ and all the people were hiding there food./ And they made stone soup with three round stones, carrots um and.../

T: Good Carrots,

C: And What else?/

T: That's okay if you don't remember anything else.

C: Um its like lettuce./

T: Okay, like lettuce, what else happened?

C: They sat at the table and ate it./

T: They sat at the table and ate it and then what happened?

C: They had a feast./

T: They had a feast and then what happened?

C: They dropped in the bed/ and then in the morning they got up./

T: Okay then what happened?

C: $\mathrm{Uh} /$

T: In the morning they got up and then what happened?

C: Um...l

T: Is there anything else?

C: No./

Child 9 Presentation: 2 Story: Strega Nona Activity: Art Group 3

C: Um um Big Anthony and um um what was the girls name?

T: Strega Nona. 
C: Strega Nona, Strega Nona told Big Anthony not to touch the pot./ And when she went to the mountain to meet her friend um he touched the pot./ And they ate spaghetti./ T: They ate spaghetti and then what happened.

C: He said the words to make it/ and then when they ate everybody got their spoons, forks and bowls and some plates./ And then he forgot to do the three kisses so it was all over the town./

T: Good. It was all over the town and then what happened.

C: Strega Nona came back./ And then at the end he had to eat all the spaghetti from Strega Nona./ And went to sleep in the bed./

\section{Child 9 Presentation: 3 Story: Blueberries Activity: Acting Group 3}

C: His mother and Sal went to pick some bhue berries on Blueberry Hill./ And some bears were on Blueberry Hill/ and they got mixed up./ Sal thought the bear was his mother/ and the cub thought Sal's mother was his mother./

$\mathrm{T}$ : Oh, Okay and then what happened?

C: And then they found each other/ and they drived back home./

T: Anything else?

C: And they ate the blueberries./

T: Okay they ate the blueberries, anything else?

C: No./

Child 9 Presentation: 4 Story: Sylvester Activity: Acting Group 3 C: Sylvester had a pebble collection/ and he found... And one rainy day he went out/ and he found a pebble/. And it was a magic pebble/ and he wished the rain went away and it went away./

T: Good, and then what happened?

C: And then he wished that the rain came back/and it came back./

T: Excellent, then what happened?

C: And uh. He made the rain lightening and thunder go away./

$T$ : Good, and then what happened.

C: And then all the dogs and piglets came looking for him. /

$\mathrm{T}$ : And then what happened?

C: And they tried on Strawberry Hill but they just sniffed rock./

$\mathrm{T}$ : Okay and then what happened?

C: There was.../ They um went to their neighbor and asked/ and he didn't see 'em/ and they didn't see 'em./

T: Okay, and then what happened?

C: I can't remember./

T: Okay they're looking for Sylvester and they couldn't find him. Then what happened after that?

C: Um they had a picnic/ and they set it on Sylvester's back of the rock./ And then he wished that he was a donkey/ and he was./ He turned back into a donkey./

T: Good and then what happened?

C: And they went home.l 
Child 10 Presentation: 1 Story: Blueberries for Sal Activity: Art Group 4

C: I don't know./

T: Could you tell me story? Tell me about the story.

C: She picked Bhueberries./

T: Okay, Sal is in the story, she picked blueberries and then what happened?

C: They got mixed up./

T: And then, Could you tell me more about that?

C: Uh she went back home./

T: Try and tell me what happened after they got mixed up?

C: They went back home./

T: They went back home. Okay. Did anything else happen in that story?

C: No./

T: Could you tell me what Little Sal and her mother were doing?

T: What were Little Sal and her mother doing?

C: (unintelligible)

T: During the story.

C: Uh picking blueberries./

T: And then what happened to Little Sal?

C: She got mixed up.l

T: She got mixed up right. Okay is there anything that happened?

C: She got mixed up by by by by when it was her mother /and the bear finded her with his mother./

T: Good. Go ahead.

C: Nothing else.

Child10 Presentation: 2 Story: Sylvester Activity: Art Group 4

C: Uh He turned into the rock./

T: Is that how the story goes?

C: Yeah./

T: That's what happens in the story. Could you tell me how the story goes?

C: Uh they sit down./

T: They sit down and then what happens?

C: Then he went out to play./ And then he went and found the lion./ His friend the lion./

T: He found the lion and then what happened?

C: He turned into a rock./

T: Okay, he turned into a rock and then what happened?

C: And his friend didn't know/ and his friend wanted to play with him./

T: Oh the friend didn't know and wanted to play with him. Okay, and then what happened?

C: His his mom and dad went for a picnic on him./

T: Really? They went for a picnic on him and then what happened?

C: He turned back into a a donkey./

T: Good, Anything else? And then what happened?

C: Nothing else./ 
Child 10 Presentation: 3

C: Uh they were hungry./

T: They were hungry, good and then what happened.

C: Uh uh They saw a village./

T: Good they saw a village and then what happened?

C: They went to all the houses./

T: They went to all the house good and then what happened?

C: They made stone soup./

T: Good, they made stone soup and then what happened?

C: They danced./

T: Okay, They danced and then what happened?

C: They got tired./

T: Okay they got tired and then what happened?

C: And then the story ended./

T: Did anything else happen in there? Could you tell me what else happened in there?

C: Nothing else happened./

T: Nothing else happened in the story? That was it?

C: Yeah./

T: Could you tell me what happened to the soldiers?

C: They sleeped in the bed./

T: They slept in the bed good anything else?

C: No./

T: How did the story end?

C: They slepted in the bed./

Child 10 Presentation: 4 Story: Strega Nona Activity: Acting Group 4 C: She said don't touch the pot./

T: She said don't touch the pot, then what happened?

C: He touched it./

T: He touched the pot and then what happened?

C: The pasta went all over the place./

$\mathrm{T}$ : The pasta went all over the place, good and then what happened?

C: The she said eat it./

T: She said eat it and then what happened?

C: He got a stomach ache./

T: He got a stomach ache and then what happened?

C: She went to sleep./

T: She went to sleep, good. What else happened in the story?

C: Nothing else./

T: Could you tell me what happened at the beginning of the story?

C: She said don't touch the pot./

T: Oh, okay she said don't touch the pot, excellent. 
Child 11 Presentation: 1 Story: Blueberries for Sal Activity: Art Group 4 C: I drawed the picture with Sally looking for Blueberries in the tree/ and she found some blueberries./ And in the picture the bird is flying and eating blueberries./

T: Do you remember the book we read? Could you tell me the story from that book?

C: I drew a picture with blueberries/ and Sally eating blueberries./

T: Okay, Sal is in this story. Could you tell me what happens to her?

C: They got mixed up./ Sal and a little bear's mother and the little bear and Sal's mother./

T: Okay, tell me about that story.

C: In the picture.../.

T: No, not about the picture the story. About Little Sal and they got mixed up, tell me more about that.

C: Little Sal, she was looking for her mother./

T: She was looking for her mother, then what happened?

C: She heard a noise in the bushes./ Then found Little Bear's mother./

T: Good then what happened?

C: Then she found her mother./

T: Good, Anything else?

C: Then they went home in the car./

T: Good, Anything else?

C: No.l

Child 11 Presentation: 2 Story: Sylvester

Activity: Art Group 4

C: I drew a picture of the rock and the lion./

T: No the story we read.

C: When he turned into a rock when he saw the lion/ and then he said "I wish I could see my mom and dad"./ and "I wish I were a donkey"./

T: Good.

C: But he had to touch the pebble to be a donkey again./

T: Oh, he had to touch the pebble to be a donkey again, okay.

C: Then his mother and father and people were looking for him/ and they went on a picnic and were happy to find him./

T: Anything else?

C: Then the lion went around and around him./

T: The lion went around and around him, and then what happened?

C: And then he walked away./

$\mathrm{T}$ : Anything else?

C: He was confused/ he turned into a rock./

T: Good, Anything else?

C: And he was sitting/ and it was lightening and thundering out./

T: Oh really? and then what happened?

C: I don't know./

T: Can you remember anything else?

C: Yeah./

T: Okay keep going and tell me about the story. 
C: The lion walked away./

T: The lion walked away, anything else?

C: No./

Child 11 Presentation: 3 Story: Stone Soup Activity: Acting Group 4

C: Well the soldier said, "Well maybe we can make some stone soup."/

T: The soldier said, We can make some stone soup, and then what happened?

C: And then they got a pot and stones to make the soup./

$\mathrm{T}$ : And then what happened?

C: They put cabbage in the soup./

T: Cabbage and then what happened?

C: They cut carrots in the soup./ And they ate all the soup./

T: And then what happened?

C: They danced./

$\mathrm{T}$ : And then what happened.

C: They cut the potatoes and other things in the soup./

$\mathrm{T}$ : And then what happened.

C: They ate the soup and went to bed./

T: Did anything else happen in the story?

C: They marched home.l

T: They marched home.

C: Then they found the village./

T: They found the village and then what.

C: Then they ate soup./

T: They ate soup, anything else? C: No./

Child 11 Presentation: 4 Story: Strega Nona Activity: Acting Group 4 C: He was not supposed to touch the pasta pot./ And she told him not to touch it./ Then she went to see some friends/ and he touched the pot./

T: Okay, and then what happened?

C: He made pasta/ and it went all over the place./

T: And then what happened?

C: It wouldn't stop./

$\mathrm{T}$ : And then what happened?

C: She looked out the window./

$\mathrm{T}$ : She looked out the window and then what happened?

C: She saw the pasta coming./

T: And then what happened?

C: She came home./

T: Strega Nona came home and then what happened?

C: She stopped it./

T: And then what happened?

C: He fed the goats and rabbits./

T: He fed the goats and rabbits, anything else? C: No./ 
Child 12 Presentation: 1 Story: Blueberries for Sal

C: Blue..../ Mother looking for her child.../

T: The mother's looking for her child. What else?

T: Tell me the story.

C: And she and big bear look behind her/ and he said "This isn't my little bear."/ "This is someone elses um child." /

T: Okay, what else?

C: Sally picking the blue berries/ and the mother looking for little Sally/ and mother said "This isn't my honey."/ And um and "I gotta go find my honey."/ and um

T: She's looking for her daughter and..

C: She's looking for the other bear who lives for this bear/ and $\mathrm{Im}$ looking for my honey./ That bear was saying/ and $\mathrm{Im}$ going to find his mother./

T: Okay and then what happened?

C: $\mathrm{Um} /$

T: There was a mother and a baby bear..

C: The bear was looking for a different one that other mother who he with./ But she left without him because he was late./ He wanted to eat more blueberries and he said wait./ But she didn't wait./ She went to find some different blueberries/ and she said "These are some different blueberries and I should put them in my pail because I think Sally will like these./ I gotta go find Sally."/ So mommy is gonna go to find my other daughter and her name is Sally./

$\mathrm{T}$ : Oh, Okay anything else?

C: No./

Child 12 Presentation: 2 Story: Sylvester Activity: Art Group 4

C: The mother and father at the window./ The mother was crying and the daddy put on the daddy put something on her/ and she and the daddy say the daddy say, "He will come back soon." /

T: He will come back soon. Then what happened?

C: And the mother said, "He need.. We needa go out for a picnic./ Maybe he'll come back then."/ And the daddy said "I think he will and I think he is."./ Cause I go just about./ Cause I go there/ and I keep people in safe but they don't mind./ Cause I go there at the picnic./ And mother bear, No mother pig. She said, "I know, let's go on a picnic for him to see if he'll come back." " "I know he will because he is./ I think doggies are looking for him/. And doggies are looking for him even behind rocks./ They don't um."/

T: What else?

C: I forgot./

T: That's okay.

C: And they went to a picnic/ and they saw him come back/ and they went back home/ and they put him in bed./ It was bedtime./ And they went in bed/ and they said "Good night|"/

T: Did anything else happen?

C: No./ 
Child 12 Presentation: 3 Story: Stone Soup Activity: Acting Group 4 C: Um he um "Do you have some food so I can eat it and put it in my soup."/ and "I gonna I know what I can put in my soup./ If someone can find carrots for me Ill put them in my soup."/ "But if they don't find carrots, then III find carrots for me, Carrots."/ " But if they can find it then I11 just cut 'em and put 'em into my soup."/ "And I gotta find some potatoes and milk so I can put it in and some sausage."/ "And I think I don't need anything else./ I think we needa dance after we eat./ Because we I don't know what else to do./ We might play a game and a few other stuff/ and then maybe we can go to bed or I think we'll have snack or well go to bed./ And Im going to bed." And then the other soldiers, the other two soldiers had snacks/ and they had the rest of the stone soup as snack./

T: Okay, Anything else?

C: And then they went to bed/ and they said, "Good night, Its morning time"./ And then soldiers ate breakfast/ and then they went out to... and then they had lunch then then dinner./ Then they played games and had/ and they eated/ and they had some for breakfast./ And they said "I have some other food right here./ I found it in the village cause some of the people were not having stone soup to eat we might go out for dinner./ Because I think we are going to go out for dinner./ All right so maybe we'll go for dinner./ I think we should and..... Im gonna put and the orange stuck in the sky./ and lets cook this stone../ I think we can have stone soup again but I can't eat it but we are./ That's what we must have./

T: Anything else?

C: That's all./

Child 12 Presentation: 4 Story: Strega Nona Activity: Acting Group 4 C: Strega Nona said "Can.. Don't touch the pot cause it , you'll get hot./ Cause its hot and if you touch it you will get hot."/ Then we all get burned/ and we all say ouch because you are Big Anthony./ And I shouldn't touch this pot./ Blow it three kisses./ Why one because he forgot them and I know how./ IIl call them over for dinner and blow the kisses./ But if I don't the hill be blanks/ and he'll have to eat til last because he's so late./ And I1l have to say come tomorrow night./ And we can have it tomorrow I guess./ Macaroni./ And Ill put it in that pan cause I don't have no other pans./ I only have this pan. / Oh are you eating by your hands?/ Because Im washing them so they're not washing another one./ And when that other one .../ I'll invite you over my house./ IIl invite you over maybe for breakfast./ And you you be rude so ..../

T: Anything else?

C: Or if I have cots, beds ... Anything Ill put you on in case you forget./ Can you bring a bowl of pebbles for me if you can?/ In case you have a lot of pebbles./ Can you bring me over some./ One day she came over.../ in case I .... A purple dish and a red dish and a pink/ So I will never forget./

T: Anything else about the story.

C: No./ 


\section{BIBLIOGRAPHY}

Alverman, D. (1991). The Discussion Web: A Graphic Aid for Learning Across the Curriculum. The Reading Teacher. 45:92-99.

Beck, Isabel L and McKeown, Margaret G. (1981). Developing Questions That Promote Comprehension: The Story Map. Language Arts. 58(8):913-918.

Berney, T.D. and Barrera, M. (1990). Language development through holistic learning. New York: Office of Research, Evaluation, and Assessment. (ERIC Document Reproduction Service No. ED 319 253.

Billingsley, Bonnie and Ferro-Almeida, Susan C. (1993). Strategies to Facilitate Reading Comprehension in Students with Learning Disabilities. Reading and Writing Quarterly. 9:263-278.

Bookbinder, J. (1975). Art and Reading. Language Arts. 52(6): 783-785,796.

Brown, Marcia (1947) Stone Soup. Macmillian Publishing Company. New York.

Culatta, B., Page, J and Ellis, J. (1983). Story Retelling As a Communicative Performance Screening Tool. Language, Speech, and Hearing Services in Schools. 14, April: 66-74.

DePaola, Tomie (1975) Strega Nona. Half Moon Books, A imprint of Simon \& Schuster. New York.

Feldman, Jean (1991). A Survival Guide for the Preschool Teacher. The Center for Applied Research in Education. New York.

Fielding, Linda G. and Pearson, P. David (1994). Reading Comprehension: What Works. Educational Leadership. February: 62-68.

Fry's Readability Graph (1969) Maginnis, George. The Reading Graph and Informal Reading Inventories. The Reading Teacher. 22, March: 518.

Glenn, C. and Stein, N. (1980) Syntactic structures and real world themes in stories generated by children (Technical Report). Urbana: University of Illinois Center for the Study of Reading.

Goldenberg, Claude (1992/1993) Instructional conversations: Promoting Comprehension through discussion. The Reading Teacher. 46,4: 316-325.

Harp, Bill (1987). When the Principal Asks: "Why are your kids doing art during reading time?". The Reading Teacher. 41,3: 346-347.

Heath, Shirley Brice (1983). Ways with Words. Cambridge University Press. New York.

Herr, Judy and Libby, Yvonne (1990). Creative Resources of the Early Childhood Classroom. Delmar Publishers, Inc. Printed in the United States of America.

Hoggan, K and Strong, C. (1994). The Magic of "Once Upon a Time": Narrative Teaching Strategies. Language, Speech, and Hearing Services in Schools. 25,April: 76-89. 
Ishee, Nell and Goldhaber, Jeanne (1990) Story Re-Enactment: Let the Play Begin! Young Children. March: 70-75.

Jansson, D.R and Schilleref, T.A. (1980). Reinforcing Remedial Readers Through Art Activities. The Reading Teacher. 33,Feb.: 548-551.

Knipping, Nancy Y. (1993) Let Drama Help Young Authors "Re-See" Their Stories. Language Arts. 70, January: 45-50.

Lasky, Lila and Mukerii, Rose. Art Basic for Young Children. The National Association for the Education of Young Children. Washington, D.C.1980-81.

Macey (1978) Combining Word Recognition with Art. The Reading Teacher. 32, Oct:64-65.

Martinez, Miriam (1993) Motivating dramatic story reenactments. The Reading Teacher. 46,8: 682688.

Maynard, John. Model Questions and Key Words to Use in Developing Questions. Based on Bloom's Taxonomy. Developed and Expanded. Pamona, California.

McCloskey, Robert (1948) Blueberries for Sal. Puffin Books. New York.

Milliken, Linda (1992) Literature Patterns, Edupress, CA.

Murrow and Smith (1990). Group Size and Story Reading. Reading Research Quarterly. XX:213-231.

Norton, Donna E. (1992) Engaging Children in Literature: Understanding plot structures. The Reading Teacher. 46,3: 254-258.

Pellegrini, A.D. (1984). Identifying Causal Elements in the Thematic-Fantasy Play Paradigm. American Educational Research Journal. 21(3):691-701.

Pellegrini, A.D. and Galda, Lee (1982) The Effects of Thematic-Fantasy Play Training on the Development of Children's Story Comprehension. American Educational Research Journal. 19,3: 443-452.

Putnam, Lynne (1991). Dramatizing Nonfiction with Emerging Readers. Language Arts. 68, Oct: 463469.

Sadoski, Mark, Goetz, Ernest T. and Fritz, Joyce B. (1993) A Causal Mode of Sentence Recall: Effects of Familiarity, Concreteness, Comprehensibility, and Interestingness. Journal of Reading Behavior. 25, 1: 5-15.

Saltz, Eli and Johnson, James (1974). Training for thematic-fantasy play in culturally disadvantaged children: Preliminary results. Journal of Educational Psychology. 66, 623-630.

Silvern, Steven B., Taylor, Williamson, Surbeck, and Kelly (1986). Young Children's Story Recall as a Product of Play, Story Familiarity, and Adult Intervention. Merrill-Palmer Quarterly. 32,1: 73-86.

Spindler, George and Louise (1987). Interpretive Ethnography of Education at Home and Abroad. Lawrence Erlbaum Associates, Inc. New Jersey. 
Steig. William (1969) Sylvester and the Magic Pebble. Simon and Schuster books for Young Readers, Divisions or Simon \& Schuster, Inc. New York.

Swanson, Lou. (1994). Changes--How Our Nursery School Replaced Adult-Directed Art Projects With Child Directed Experiences and Changed to an Accredited, Child-Sensitive, Developmentally Appropriate School. Young Children. May: 69-73.

Watson (1994). Enhancing Literacy. Language, Speech, and Hearing Services in Schools. 25, July: 136-145.

White Otto, Beverly (1993). Signs of Emergent Literacy Among Inner-City Kindergartners in a Storybook Reading Program. Reading and Writing Quarterly. 9:151-162. 